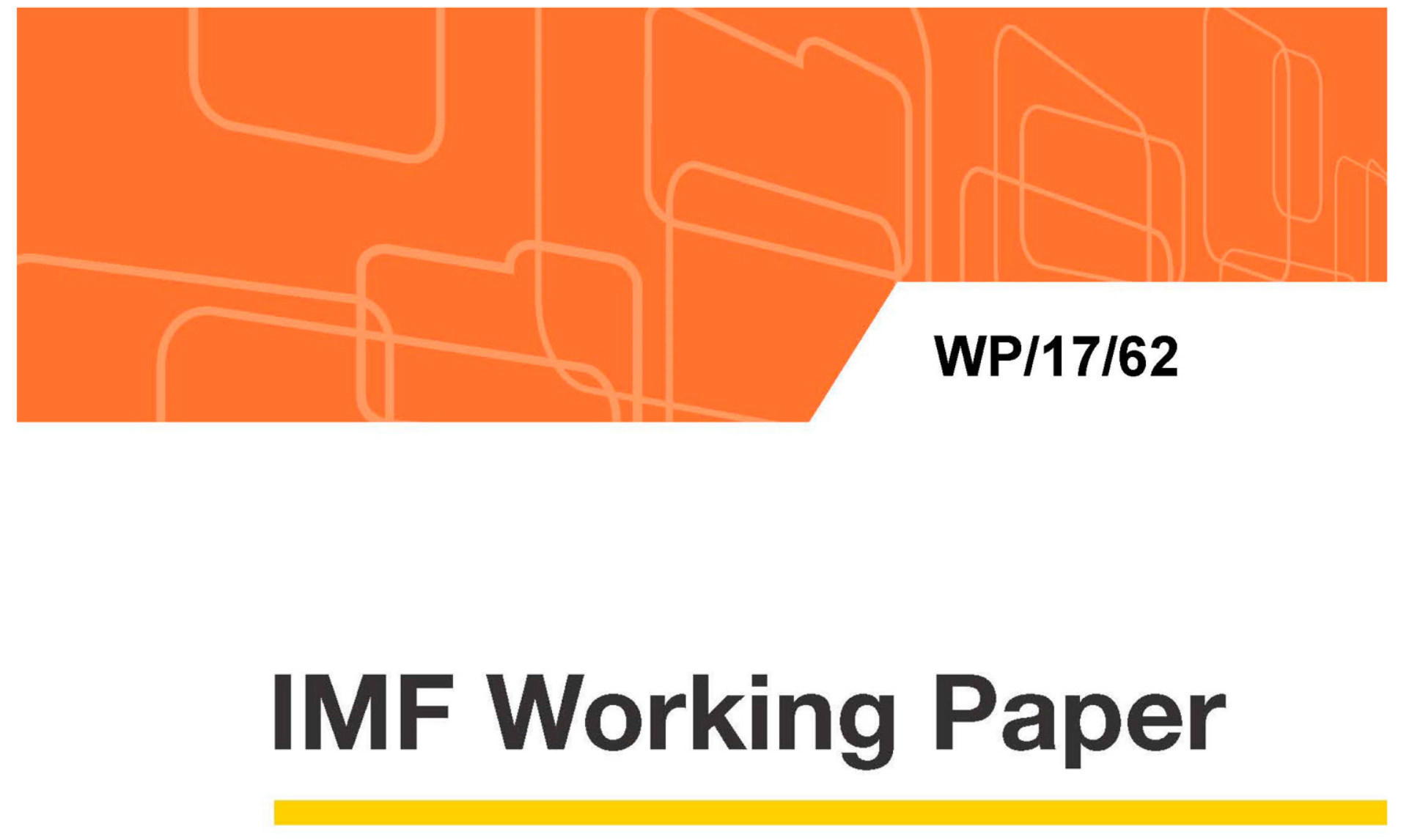

\title{
Lower Bound Beliefs and Long-Term Interest Rates
}

by Christian Grisse, Signe Krogstrup, and Silvio Schumacher

IMF Working Papers describe research in progress by the author(s) and are published to elicit comments and to encourage debate. The views expressed in IMF Working Papers are those of the author(s) and do not necessarily represent the views of the IMF, its Executive Board, or IMF management. 


\section{WP/17/62}

\section{IMF Working Paper}

\section{Lower Bound Beliefs and Long-Term Interest Rates}

by Christian Grisse, Signe Krogstrup, and Silvio Schumacher

IMF Working Papers describe research in progress by the author(s) and are published to elicit comments and to encourage debate. The views expressed in IMF Working Papers are those of the author(s) and do not necessarily represent the views of the IMF, its Executive Board, or IMF management.

I N T E R N A T I O N A L M O N E T A R Y F U N D 


\title{
IMF Working Paper
}

\author{
Research Department
}

\section{Lower Bound Beliefs and Long-Term Interest Rates*}

Prepared by Christian Grisse, Signe Krogstrup, and Silvio Schumacher

Authorized for distribution by Signe Krogstrup

March 2017

IMF Working Papers describe research in progress by the author(s) and are published to elicit comments and to encourage debate. The views expressed in IMF Working Papers are those of the author(s) and do not necessarily represent the views of the IMF, its Executive Board, or IMF management.

\begin{abstract}
We study the transmission of changes in the believed location of the lower bound to longterm interest rates since the introduction of negative interest rate policies. The expectations hypothesis of the term structure combined with a lower bound on policy rates suggests that normal policy transmission is reduced when policy rates approach this lower bound. We show that if market participants revise downward the believed location of the lower bound, this may in itself reduce long-term yields. Moreover, normal policy transmission to long-term rates increases. A cross-country event study suggests that such effects have been empirically relevant during the recent negative interest rate episode.

JEL Classification Numbers: E43, E52

Keywords: monetary policy, negative interest rates, lower bound, yield curve, term structure

Author's E-Mail Address: christian.grisse@snb.ch, skrogstrup@imf.org, silvio.schumacher@snb.ch

\footnotetext{
* We thank Ran Bi, Hans Dewachter (discussant), James Hamilton (discussant), Emanuel Mo“nch, Thorvardur Olafsson, Rafael Repullo, Eric Swanson, Andreea Vladu (discussant) and participants at the ECB workshop on negative interest rates, the Bundesbank-OeNB-SNB research workshop and the Annual International Journal of Central Banking Research Conference 2016 for comments and suggestions. We also thank Rafael Greminger for excellent research assistance. The views in this paper are solely the responsibility of the authors and do not necessarily reflect the views of the Swiss National Bank, the International Monetary Fund, its Management or its Board.
} 


\title{
Lower bound beliefs and long-term interest rates*
}

\author{
Christian Grisse \\ Swiss National Bank
}

\author{
Signe Krogstrup \\ International Monetary Fund
}

This version: March 2017

\author{
Silvio Schumacher \\ Swiss National Bank
}

\begin{abstract}
We study the transmission of changes in the believed location of the lower bound to longterm interest rates since the introduction of negative interest rate policies. The expectations hypothesis of the term structure combined with a lower bound on policy rates suggests that normal policy transmission is reduced when policy rates approach this lower bound. We show that if market participants revise downward the believed location of the lower bound, this may in itself reduce long-term yields. Moreover, normal policy transmission to long-term rates increases. A cross-country event study suggests that such effects have been empirically relevant during the recent negative interest rate episode.
\end{abstract}

JEL classification: E43, E52

Keywords: monetary policy, negative interest rates, lower bound, yield curve, term structure

\footnotetext{
*Contact: christian.grisse@snb.ch, skrogstrup@imf.org, silvio.schumacher@snb.ch. We thank Ran Bi, Hans Dewachter (discussant), James Hamilton (discussant), Emanuel Mönch, Thorvardur Olafsson, Rafael Repullo, Eric Swanson, Andreea Vladu (discussant) and participants at the ECB workshop on negative interest rates, the Bundesbank-OeNB-SNB research workshop and the Annual International Journal of Central Banking Research Conference 2016 for comments and suggestions. We also thank Rafael Greminger for excellent research assistance. The views in this paper are solely the responsibility of the authors and do not necessarily reflect the views of the Swiss National Bank, the International Monetary Fund, its Management or its Board.
} 


\section{Introduction}

Policy interest rates were reduced to near zero in many countries in the aftermath of the global financial crisis. Because zero was broadly believed to be the lower bound on interest rates, further monetary loosening was achieved mainly through quantitative policy tools. More recently, however, some central banks cut their policy rates into negative territory. Danmarks Nationalbank, the Danish central bank, was a pioneer in cutting its policy rate to -25 basis points in mid-2012. ${ }^{1}$ The European Central Bank (ECB) cut its policy rate below zero in mid-2014, which was followed by incremental rate cuts below zero by the Swiss National Bank (SNB), Danmarks Nationalbank and Sveriges Riksbank. The Bank of Japan cut its main policy rate to -10 basis points in January 2016. The SNB has gone furthest with negative policy rates by introducing negative interest rates of -75 basis points on banks' sight deposit account balances, which have remained in place since January 2015.

As policy rates have been cut below zero, the market's belief about the location of the lower bound on nominal interest rates has also moved into negative territory. The lower bound remains unknown, however. We refer to the level of the policy interest rate that markets broadly believe is the lower bound as the believed lower bound.

Interest rate policy transmits to the real economy through its effect on the broader term structure of interest rates, and in normal times, this transmission is not constrained by the lower bound on interest rates. When the policy rate is very low or negative, the distance to the believed lower bound narrows, and room for future downward movements in policy rates shrinks. Ruge-Murcia (2006) uses a very simple two-period term structure model to show that this reduces the transmission of short-term policy rate cuts to long-term interest rates. RugeMurcia (2006) and Grisse (2015) present empirical evidence based on US and Japanese data suggesting that the transmission of short-term rates to long-term rates is indeed reduced when policy rates are closer to zero. We argue and provide empirical evidence that if rate cuts below zero simultaneously move the market's believed location of the lower bound, this influences the distribution of possible future short-term policy rates and may thus directly move long-term interest rates and restore policy transmission.

We first theoretically study the transmission of changes in the believed location of the lower bound to long-term interest rates. To motivate our empirical analysis, we extend the theoretical term structure model of Ruge-Murcia (2006) to show that when short-term interest rates are held constant, a drop in the believed lower bound leads to a drop in longer-term interest rates, but only when long-term interest rates are initially constrained by the lower bound on short rates. This mechanism has also been highlighted by Kortela (2016) and Vladu and Lemke (2016) based on much more sophisticated shadow rate term structure models. The advantage of illustrating this point with the Ruge-Mucia model is that it is analytically very simple and intuitive, though at the cost of simplifying other factors that drive yield curve variation. Second, we empirically study the predictions of the model by using an event study of

\footnotetext{
${ }^{1}$ Sweden had a brief period of a negative rate on its deposit facility in 2009 , but this rate was not effectively binding for money markets and hence did not transmit to financial markets.
} 
a panel of advanced countries. To measure changes in the believed location of the lower bound, we focus on central bank announcements of interest rate cuts into negative territory, which likely departed from conventional wisdom on the location of the lower bound. We conjecture that such announcements changed the perception of the lower bound in not only announcing countries but also across countries more broadly. In other countries, short-term policy rates would have remained unchanged on these occasions. By focusing on the effects of such announcements on other countries' long-term interest rates and relating these effects to the initial level of short-term interest rates across countries, we can identify the effect of changes in the perceived location of the lower bound independently from the effect of policy rate changes and more standard international interest rate spillovers. Our results lend support to the model's prediction.

There are important policy implications of these findings. In the vicinity of the lower bound on interest rates, central bank actions or communication that result in a downward shift in the believed lower bound can reduce longer-term interest rates and thereby achieve monetary policy loosening independently of short rate cuts. Such actions or communication can also increase the distance of the policy rate to the believed lower bound, thereby increasing monetary policy effectiveness. Managing market perceptions regarding the location of the lower bound is an important dimension of effective central bank communication when policy rates are low.

Our paper is related to the two previously mentioned papers that investigate the implications of a changing lower bound for monetary policy transmission in the context of shadow rate term structure models. Based on their model, Lemke and Vladu (2016) use survey expectations on interest rates in the euro area to argue that there were two changes in the market-perceived lower bound prior to 2015: a first change in May 2014 (when some forecasters started to predict an ECB rate cut to -10 basis points at the June 2014 meeting) and a second change in September 2014 (when the ECB's 10bp rate cut took markets by surprise). According to their model, the decline in euro area yields around the ECB's September 2014 rate cut was exclusively driven by changes in the lower bound. Kortela (2016) also estimates a shadow rate term structure model using euro area data, but the lower bound is allowed to vary gradually over the sample. Considering alternative exogenous processes for the lower bound, Kortela (2016) finds that models with a time-varying lower bound fit the data better than constant lower bound models. The model also suggests that lower bound changes were the main driver of euro area 2-year yield movements between September 2014 and January 2016. In contrast, the contribution of lower bound changes to changes in 10-year yields is found to be small. Our paper is the first to consider the effects of changes in the believed location of the lower bound on long-term yields in broader panel data on all five countries that have moved policy rates into negative territory.

The remainder of this paper is structured as follows. The next section presents and extends the Ruge-Murcia (2006) model, which motivates the empirical analysis and identification strategy. The empirical analysis is presented in Section 3, and Section 4 concludes. The appendix contains supporting material. 


\section{Theory}

With the purpose of deriving an empirical identification strategy for assessing the relevance of changes in markets' perceptions of the location of the bound, we turn to the very simple two-period term structure model with a lower bound derived in Ruge-Murcia (2006). ${ }^{2}$ The Ruge-Murcia model is highly intuitive and can be solved analytically, but it nevertheless has sufficient richness to allow us to characterize the lower bound effects on long-term rates in which we are interested. We extend the Ruge-Murcia model to allow for the lower bound to be different from zero and derive the impact of a change in this lower bound on longer-term interest rates. In the empirical approach, we proxy changes in the believed location of the lower bound by central bank announcements of policy rates moving into negative territory. This gives rise to the empirical identification problem that both changes in short-term interest rates and changes in the believed lower bound affect long-term rates and occur at the same time. In Section 3, we use the model to derive the conditions under which the presence of shifts in the believed lower bound can be identified in the data.

The short-term interest rate $r_{t}$ is constrained by a lower bound,

$$
r_{t}=\max \left(r_{t}^{*}, \bar{r}\right)
$$

where $r_{t}^{*}$ is the "shadow" short rate and $\bar{r}$ is the level of the nominal interest rate that market participants jointly believe is the lower bound. This believed lower bound is non-stochastic, and we treat it as exogenous in the model in order to derive very simple derivatives with respect to this level. We assume that it is equal to or below the period one level of the short-term interest rate.

While it is outside the model, we can think of the empirically unobservable believed lower bound as being influenced by observable factors that are believed to influence the location of the actual lower bound. The absolute or "true" lower bound is the level at which a further interest rate cut will cause prohibitive financial upheaval - or the level at which the central bank is simply unwilling to move the policy rate further down, independently of such financial market reactions. Prohibitive financial upheaval, for example, could be a large-scale demand for zero-interest rate physical cash in exchange for bank deposits or other assets, effectively precluding the transmission of the rate cut to the broader financial markets. A central banks' unwillingness to reduce the policy rate in the absence of such prohibitive financial upheaval can be driven by cultural, communication or political economy considerations. Negative interest rates have turned out to be unpopular and difficult to understand for the broader population, giving rise to difficult challenges with communication. Central banks' assessment of the degree to which banks are willing to transmit negative interest rates may also matter. Banks' reactions to rate cuts below zero matter for the expected effectiveness of the transmission of a policy rate cut through the bank lending channel, which may change the cost-benefit analysis of a rate cut

\footnotetext{
${ }^{2}$ Ruge-Murcia (2006) shows that his results also apply to a more general setting with an $n$-period bond, a more general stochastic process for the shadow short rate, and non-normally distributed shocks. However, in this more general setting, no closed-form solution exists, and the model properties can only be explored numerically.
} 
for central banks. ${ }^{3}$ They also matter for the expected transmission of negative rates to retail deposits, which may increase the risk of a large-scale shift into cash directly; see also Danthine (2016). The design features of negative policy rates that matter for how bank profits are affected, such as the central bank operating framework and possible exemptions to the negative interest rate on central bank reserves, may thus also matter for the location of the "true" lower bound.

The discussion suggests that the location of the lower bound is multifaceted, country specific, perhaps time varying, and very difficult to estimate. It is as of yet unobserved, but the market forms a belief about the location of this lower bound, depending on perceptions of financial market structure and preparedness, the central bank operating framework, and cultural and political considerations. As long as the believed lower bound is below the prevailing policy interest rate level and the true lower bound is unobserved, it is the believed lower bound that matters for expectations about future interest rates.

The shadow short-term interest rate depends on past short-term rates,

$$
r_{t}^{*}=\alpha+\psi r_{t-1}+\varepsilon_{t}
$$

where $\psi>0$, such that interest rates are positively autocorrelated, and $\varepsilon_{t} \sim N\left(0, \sigma^{2}\right)$. The model is reduced to the setting of Ruge-Murcia (2006) if $\bar{r}=0$. When $r_{t}^{*}<\bar{r}$, the shadow rate is unobserved, and market participants have to form expectations about $r_{t}^{*}$ conditional on variables observed up to and including period $t .^{4}$

Finally, the yield of a 2-period bond $R_{t}$ is determined by the expectations hypothesis,

$$
R_{t}=\frac{1}{2}\left(r_{t}+\mathbb{E}\left(r_{t+1}\right)\right)+\theta_{t}
$$

where $\theta_{t}$ is a liquidity and term premium, which is assumed to be uncorrelated with $\varepsilon_{t}$.

To solve the model and express $R_{t}$ as a function of $r_{t}$, we have to compute $\mathbb{E}\left(r_{t+1}\right)$. This is done in the following proposition, which is proved in Ruge-Murcia (2006) for the case where $\bar{r}=0$.

Proposition 1 The expected future short rate is given by

$$
\mathbb{E}\left(r_{t+1}\right)=\bar{r}+\left(\alpha+\psi r_{t}-\bar{r}\right)\left(1-\Phi\left(c_{t+1}\right)\right)+\sigma \phi\left(c_{t+1}\right)
$$

where

$$
c_{t+1} \equiv \frac{\bar{r}-\mathbb{E}\left(r_{t+1}^{*}\right)}{\sigma}=\frac{\bar{r}-\left(\alpha+\psi r_{t}\right)}{\sigma}
$$

and $\Phi(\cdot)$ and $\phi(\cdot)$ denote the standard normal cumulative and density functions.

\footnotetext{
${ }^{3}$ One way to think about this bank transmission channel is the reversal rate, as in Brunnermeier and Koby (2016).

${ }^{4}$ One would expect that $\mathbb{E}\left(r_{t+1}\right) \geq \bar{r}$. From (4), a sufficient condition for this to be the case is that $c_{t+1} \leq 0$, or equivalently, $\mathbb{E}\left(r_{t+1}^{*} \mid I_{t}\right)=\alpha+\psi r_{t} \geq \bar{r}$. Since $r_{t} \geq \bar{r}$, we require $\alpha /(1-\psi) \geq \bar{r}$. Assuming that $|\psi|<1$, this inequality suggests that the unconditional mean of $r_{t}^{*}$ needs to be above the lower bound on $r_{t}$. However, this condition is not relevant any more if, as in the general model in Ruge-Murcia (2006), additional exogenous variables are added to the shadow rate process (2).
} 
Proof. See Appendix A.

Here, $c_{t+1}$ can be understood as a summary measure of the degree to which the policy rate will be constrained by the believed lower bound in period two. Substituting (4) into (3) gives the solution for the long-term bond yield,

$$
R_{t}=\frac{r_{t}+\bar{r}}{2}+\frac{1}{2}\left(\alpha+\psi r_{t}-\bar{r}\right)\left(1-\Phi\left(c_{t+1}\right)\right)+\frac{\sigma}{2} \phi\left(c_{t+1}\right)+\theta_{t}
$$

The main results of Ruge-Murcia (2006) immediately follow from the first and second derivatives of (6). Not surprisingly, we have

$$
\frac{\partial R_{t}}{\partial r_{t}}=\frac{1}{2}+\frac{\psi}{2}\left(1-\Phi\left(c_{t+1}\right)\right)>0
$$

However, the response of long yields to short rate movements is stronger if interest rates are higher:

$$
\frac{\partial^{2} R_{t}}{\partial r_{t}^{2}}=\frac{\psi^{2}}{2 \sigma} \phi\left(c_{t+1}\right)>0
$$

This result implies that as nominal interest rates approach the lower bound, the response of longer-term yields to short rate changes declines. This nonlinearity arises because of the effect of $r_{t}$ on $\mathbb{E}\left(r_{t+1}\right)$, through the expectations hypothesis of the term structure. The intuition for these results is similar to that for the "honeymoon" effect (the nonlinear relationship between the exchange rate and its fundamentals) in Krugman's (1991) target zone model. Suppose that market participants think that future positive and negative interest rate shocks are equally likely. In addition, suppose that short-term rates are at $0.5 \%$, with a lower bound of zero. Then, a future shock to the shadow short rate of +1 percentage points would raise short rates to $+1.5 \%$, while a shock of -1 percentage points would only lower short rates to zero. Because market participants anticipate that future short rate shocks are constrained by the lower bound on nominal interest rates in this way, expected future short rates and hence the yield curve are affected even when short rates are still above the lower bound. When short rates are closer to the lower bound, a short rate decline will produce a smaller downward shift in expected future short rates and therefore also a smaller effect on long-term yields.

We have thus far assumed that $\bar{r}$ is fixed. Now consider a surprise change in the lower bound, for example, due to a central bank announcement: in $t$, the lower bound unexpectedly changes, but market participants assume that $\bar{r}$ will remain fixed at the new value from $t$ onward. In this exercise, we keep the current short rate $r_{t}$ unchanged, as would be the case if the central bank communicates that policy rates are possible at levels below the current believed location of the lower bound - or if the revision in market views about the lower bound reflects the actions of a foreign central bank. From (6), we have

$$
\frac{\partial R_{t}}{\partial \bar{r}}=\frac{1}{2} \Phi\left(c_{t+1}\right)>0
$$

It is intuitive that this expression is positive, for the same reasons as outlined in the previous 
paragraph. ${ }^{5}$ Furthermore, as expected, $\partial R_{t} / \partial \bar{r}$ is increasing in $c_{t+1}$, i.e., a change in market views of the lower bound matters most in a situation where short rates are already constrained. From the definition of $c_{t+1}$, it follows that

$$
\frac{\partial^{2} R_{t}}{\partial \bar{r} \partial r_{t}}=-\frac{\psi}{2 \sigma} \phi\left(c_{t+1}\right)<0
$$

Figure 1 depicts the relationship between the short-term policy rate and the long-term interest rate based on a simulation of the model, for two different levels of the lower bound. The black line reflects the relationship given a believed lower bound of zero, whereas the gray dotted line reflects a believed lower bound below zero. The black line has more curvature around zero, reflecting a higher degree of constraint emanating from the assumed belief that interest rates cannot go below zero in the second period. When the believed lower bound shifts downward into negative territory, the long-term interest rate shifts down given the policy rate, and this downward shift is greater when the policy rate is closer to the initial location of the believed lower bound.

[Figure 1 about here]

In our empirical identification strategy, we utilize the finding that the closer the policy rate to the perceived lower bound, the weaker the effect of changes in short-term interest rates on long-term rates, but the stronger the effect of changes in the believed lower bound on long-term interest rates.

\section{An Event Study of Changes in the Lower Bound}

The model shows that when the believed location of the lower bound decreases, this reduces long-term interest rates to the extent that these are already constrained by the lower bound. According to (9), the model predicts that the decrease in the long-term interest rate associated with a decrease in the believed location of the lower bound is positively related to the proximity of the lower bound. We empirically assess this prediction by using an event study approach for a panel of 14 advanced economies. Empirically, we proxy changes in the believed lower bound by unexpected central bank announcements of policy rate cuts below zero. To study the effects in a panel of countries, we conjecture that unexpected central bank cuts below zero have affected the believed lower bound globally and not just in the interest rate-cutting country. We then study how long-term yields have reacted across countries to such announcements. There are a number of identification challenges with this approach, as well as event study design issues, and we first discuss how we address these.

\subsection{Identification}

To identify changes in the believed location of the lower bound, we assume that central bank announcements of interest rate cuts that departed from conventional wisdom regarding the

\footnotetext{
${ }^{5}$ The same result is derived in the more sophisticated term structure model of Vladu and Lemke (2016).
} 
location of the lower bound are likely to have moved the perceived location of the lower bound down. We also assume that such announcements changed the believed location of the lower bound in countries that did not simultaneously change their short-term policy rates. By focusing on the reaction of yields in non-announcing countries, the theoretical framework allows us to identify the presence of changes in the perceived location of the lower bound on long-term interest rates. To do this, we first make the following assumption:

Assumption 1. The cross-country variation in the effect on the country-specific believed lower bound in non-announcing countries is independent of the interest rate level in those countries.

Practically, we think of the change in the believed lower bound in country $i$ at time $t, \Delta \bar{r}_{i, t}$, as being proportional to the change in the policy rate in the announcing country, $\Delta r_{t}$ :

$$
\begin{aligned}
\Delta \bar{r}_{i, t} & =\gamma \Delta r_{t}+v_{i, t} \\
\gamma & >0
\end{aligned}
$$

where $v_{i, t}$ are independently distributed errors that capture country-specific factors influencing the strength of the revision in the believed lower bound. Expression (11) implies that the change (though not necessarily the level) of the believed lower bound across non-announcing countries $i$ in response to a negative interest rate announcement in period $t$ is proportional to the unexpected part of the cut in the announcing country. We do allow for this effect to be smaller in non-announcing countries than the effect on the believed lower bound in the announcing country, however (e.g., if $\gamma<1$ ). A rate cut below zero could affect the believed lower bound more in the rate cutting country than in other countries if the believed lower bound also captures an assessment of how far a particular central bank is ready to cut rates, for example, based on the degree of conservatism of the institution and country or the country-specific state and readiness of the financial sector with respect to negative rates.

Assumption 1 means that the effect on the believed lower bound in other countries is independent of the prevailing interest rate level in those other countries (i.e., the country-specific error term is independent of the interest rate level). We think that this assumption is reasonable. Possible cross-country variation in the effect of a rate cut in other countries' believed lower bound is likely to depend notably on country-specific features as mentioned above, but such characteristics in turn are unlikely to be structurally linked with the interest rate level. Assumption 1 is actually stronger than required for our purposes. In fact, we require only that $\Delta \bar{r}_{i, t}$ is not positively related to $r_{i, t}$ (i.e. that beliefs are not revised downward more in higher-interest rate countries). One could perhaps argue that for behavioral reasons, updates to the believed lower bound occur only (or are larger) if the interest rate is sufficiently low. For example, in a rational inattention setting where belief updating is costly, investors may be more likely to contemplate the implications of foreign announcements for the domestic lower bound if interest rates are sufficiently close to the lower bound already. In this case, the strength of belief revisions would depend negatively on $r_{i, t}$. This does not affect our identification strategy, which relies on the idea that changes in lower bound beliefs are the only mechanism that generates a negative 
correlation between the strength of changes in long-term yields and the policy rate changes.

The selection of the relevant set of belief-changing central bank announcements is not straightforward. There are no data or surveys that provide systematic information on changes in the market's belief about the location of the lower bound. It is very difficult to come up with objective criteria for selecting announcements that are likely to be associated with changes in the believed lower bound. Identification hence has to rely on a certain amount of judgment. To remain as general and objective as possible but with the risk of selecting announcements that are not associated with changes in the believed location of the lower bound, our baseline includes all central bank announcements of leading policy rate cuts into, or further into, negative territory that were unexpected. ${ }^{6}$ This event selection strategy may increase the amount of noise in the independent variable, which could give rise to attenuation bias. This would stack the odds against finding significant effects, suggesting that the effects may be even stronger than those suggested by our estimates. Table 1 presents all the announcements made to date of leading policy rate cuts in negative territory. Column 6 contains the part of the announced cut that was unexpected, as measured by Bloomberg's survey of financial market participants. We thus select the 12 announcements that contained an element of surprise according to the Bloomberg survey.

[Table 1 about here]

As it is unlikely that all these announcements had similar effects on the believed lower bound, we also consider alternative announcement selections. For example, later cuts into negative territory could have been less belief changing than early ones, where interest rates went below levels never seen before. As a robustness check of our baseline, we therefore also consider the subset of "new global lows" (i.e., interest rate cuts that moved a policy rate below levels previously seen). This subset comprises the two announcements by the SNB, as earlier announcements by Danmarks Nationalbank that first brought interest rates into negative territory were anticipated. We also consider a sample that excludes country observations where the policy rate of the country in question was already lower than that reached by the announcing country. The drawback of these two subsets, particularly the former, is that the number of observations is reduced.

A second identification challenge is that policy rate cuts may also affect long-term interest rates through the normal channels of the term structure of interest rates. As discussed above and as shown by the model, a policy rate cut directly affects long-term yields in the announcing country through the expectations channel of the term structure, but we remove this direct impact by considering only how long-term interest rates respond in non-announcing countries.

\footnotetext{
${ }^{6}$ We select only cuts below zero for the policy rate that transmit to money markets and do not consider cases where interest rates on central bank deposit facilities were cut into negative territory when the leading policy rate has remained positive. The first announcement by Riksbank in 2009 of a negative interest rate on its deposit facility did not effectively bind or transmit to money markets and is hence unlikely to have changed perceptions of how much interest rates could be cut below zero. More recently, both Norway and Hungary cut the rate on their deposit facilities below zero while keeping the leading policy rate positive. We do not consider these announcements to be relevant either.
} 
There may still be indirect effects through standard policy spillovers, however. These could be in the form of spillovers of policy rate moves to foreign policy rate moves, to expected future policy moves (i.e., lower for longer expectations), or through the term premium. Note first that our model suggests that if policy interest rates move in other countries in response to an unexpected interest rate cut below zero, the isolated effect on long-term yields would be smaller when it is closer to the lower bound, given the believed lower bound, which is opposite of the effect of a reduction in the believed lower bound. We briefly discuss the implications of other types of spillovers for our identification strategy here.

Consider the case where an unexpected negative interest rate announcement influences longterm yields in other countries through the expected duration of the other countries' own lowinterest rate regime. Even if an unexpected cut below zero does not lead to a higher likelihood of policy rate cuts in other countries, it could still lead market participants to believe that policy rates will stay low for longer than previously believed. This channel can be captured in our theoretical framework by assuming that foreign interest rate cuts reduce $\alpha$ and thus reduce the long-term average interest rate level. Alternatively, one could assume that the shock to the second-period interest rate $\varepsilon_{t+1}$ has a non-zero mean $\mu$, with foreign negative interest rate announcements lowering $\mu$. These two formulations give identical results, so we focus here on the case where $\alpha$ changes. One finds that a decrease in $\alpha$ lowers long-term yields,

$$
\frac{\partial R_{t}}{\partial \alpha}=\frac{1}{2}\left(1-\Phi\left(c_{t+1}\right)\right)>0
$$

This effect is stronger if interest rates are higher:

$$
\frac{\partial^{2} R_{t}}{\partial \alpha \partial r_{t}}=\frac{1}{2 \sigma} \phi\left(c_{t+1}\right)>0
$$

Thus, just as in the case of an effect of foreign interest rate cuts on domestic short rates, we find that a potential "lower for longer" effect of foreign interest rate cuts would induce a positive correlation between changes in long-term yields and interest rate levels.

Now consider spillovers through term premiums. The term premium in the model of RugeMurcia (2016) plays no important role: they are shocks that are assumed to be uncorrelated with all other variables in the model. In practice, however, movements in term premiums are important drivers of bond yield movements and likely to be endogenous, notably to policy moves and expectations. For example, announcements of cuts into negative territory were on some occasions accompanied by announcements of QE, and the associated portfolio balance effects on term premiums on government bonds could spill over to term premiums on assets in other countries. Moreover, it is often argued that cuts below zero are considered a sign of desperation in financial markets, resulting in higher risk premiums. This could increase the term premium but could also reduce it if the underlying instruments are considered safe (flight to safety). The empirical literature finds that term premiums are indeed an important source of variation and that they respond to monetary policy. For example, Crump et al. (2016) find that for maturities greater than 3 years, term premiums explain more than $90 \%$ of the variation in

\section{CInternational Monetary Fund. Not for Redistribution}


the changes in bond yields. Crump et al. (2016) and Abrahams et al. (2016) also find that term premiums increase in response to expansionary monetary policy shocks.

These findings are consistent with those of Rudebusch and Swanson (2012), who link an expansionary monetary policy surprise to expectations that economic activity will be higher and hence that marginal utility will be lower in the period when nominal bonds pay off. This makes bonds a less attractive investment, lowering their prices through a higher term premium. In contrast, Hanson and Stein (2015) argue that the decline in long-term real forward rates to surprise policy rate cuts is due to declines in the term premium - i.e., short-term rates and term premiums move in the same direction in response to monetary policy shocks. They build a model where the reaction of term premiums to policy shocks is due to the presence of yieldoriented investors. In response to a surprise interest rate cut, these investors rebalance their portfolios toward longer-term bonds in order to mitigate the decline in their average portfolio yield. The resulting increased demand for longer-term bonds raises their prices and lowers the term premium.

If monetary policy surprises affect term premiums, the relevance of this for identification depends on how it is related to the interest rate level. We are not aware of any studies that directly examine this link. Neither of the theoretical contributions mentioned above model the lower bound explicitly. Introducing a lower bound in these models could limit the response of term premiums to shocks, which would suggest that if anything, the spillovers through term premiums could be either independent of the interest rate level or increasing in this level. This is opposite of the relation with the interest rate level suggested by changes in the believed lower bound. Potential spillovers through the term premium should therefore not affect our identification strategy. ${ }^{7}$

In general, the lower the interest rate level, the less standard policy spillovers should be able to influence long-term yields because of the lower bound constraint. In contrast, the closer a country to the lower bound, the larger the potential effect of a downward shift in the believed lower bound on interest rates. If an announcement has larger effects on long-term interest rates in countries that are closer to the lower bound than in countries that are further away from the lower bound, it implies that the believed lower bound is shifting down and that this effect is outweighing possible opposite effects of standard spillovers through policy expectations and risk premiums. We use these observations to formulate a sufficient condition for belief effects on long-term interest rates to be present.

To make this point more formally, consider a central bank that announces a surprise cut of its policy rate into negative territory, $d r_{t}<0$. The effect on the long-term yield $R_{i t}$ in another country $i$ is

$$
\frac{d R_{i t}}{d r_{t}}=\frac{\partial R_{i t}}{\partial r_{i t}} \frac{d r_{i t}}{d r_{t}}+\frac{\partial R_{i t}}{\partial \bar{r}_{i t}} \frac{d \bar{r}_{i t}}{d r_{t}}
$$

The first term on the right-hand side reflects a standard policy spillover effect through expected policy actions or the term premium. ${ }^{8}$ The second term reflects the effect of changes in the

\footnotetext{
${ }^{7}$ Their presence could set the bar higher for identification, however.

${ }^{8}$ We have not included other standard spillovers such as changes in policy expectations (lower for longer) or
} 
believed lower bound, and it is this effect that we are interested in identifying. If short-term interest rates do not respond to cuts in policy rates in other countries, then the identification problem is solved. ${ }^{9}$ This would be a reasonable expectation if the announcing country is small in financial markets in comparison with country $i .{ }^{10}$ It is nevertheless unlikely to be a good description of the data when the announcing country is influential in global financial markets or if the announcement is unusual and commands attention. We therefore rely on the predictions of the extended Ruge-Murcia (2006) model for identification. Consider how the above change in long-term yields depends on the interest rate level in country $i$. From (14), we have

$$
\frac{d^{2} R_{i t}}{d r_{t} d r_{i t}}=\frac{\partial^{2} R_{i t}}{\partial r_{i t}^{2}} \frac{d r_{i t}}{d r_{t}}+\frac{\partial R_{i t}}{\partial r_{i t}} \frac{d^{2} r_{i t}}{d r_{t} d r_{i t}}+\frac{\partial^{2} R_{i t}}{\partial \bar{r}_{i t} \partial r_{i t}} \frac{d \bar{r}_{i t}}{d r_{t}}+\frac{\partial R_{i t}}{\partial \bar{r}_{i t}} \frac{d^{2} \bar{r}_{i t}}{d r_{t} d r_{i t}}
$$

The first two terms on the right-hand side capture traditional spillover effects on interest rates and how these vary with the interest rate level in country $i$. The last two terms capture how the effect of changes in the believed lower bound on long-term interest rates depend on the interest rate level. We now make Assumption 2:

Assumption 2. Short-term interest rates in country $i$ either do not respond to changes in the policy rate of the announcing country or move in the same direction as policy rates in the announcing country: $d r_{i t} / d r_{t} \geq 0$.

Given business cycle synchronization and the positive correlation of central bank policy rates across advanced economies, we consider it likely that this assumption is fulfilled in the data. Assumption 2 together with equation (8) above, which says that $\partial^{2} R_{i t} / \partial r_{i t}^{2}>0$, imply that the first term on the right-hand side of (15) is non-negative. Note that the model prediction in equation (8) has been validated in time-series studies by Ruge-Murcia (2006) for Japan and Grisse (2015) for the US. Related evidence is provided by the finding by Swanson and Williams (2014) and others that bond yield responses to macroeconomic data surprises have declined as interest rates approached the lower bound. We therefore expect equation (8) to also hold in the cross-section of advanced economies. These studies include all spillover effects, including those through term premiums and expectations of future policy action.

The second term on the right-hand side of (15) is positive. We know this because Equation (7) says that $\partial R_{i t} / \partial r_{i t}>0$. Moreover, $d^{2} r_{i t} / d r_{t} d r_{i t}=d r_{i t} / d r_{t} \geq 0$ by Assumption 2.

Now consider the third term on the right-hand side of (15). Equation (10) above says that $\partial^{2} R_{i t} / \partial \bar{r}_{i t} d r_{i t}<0$. Therefore, if $d \bar{r}_{i t} / r_{t}>0$, the third term is negative.

Assumption 1 together with equation (9) above, which says that $\partial R_{i t} / \partial \bar{r}_{i t}>0$, imply that the last term on the right-hand side of (15) is non-positive.

changes in the term premium here. These effects could easily be included, however, by modeling the effects on future policy expectations through a shift in the mean error of the interest rate process. A spillover through the term premium could be included through $d \theta_{t} / d r_{t}$.

${ }^{9}$ Note that in the version of the Ruge-Murcia (2006) model discussed in section $2, d r_{i t} / d r_{t}=0$ holds by assumption. However, the model can be easily generalized by including foreign interest rates as an exogenous variable in the stochastic process for the shadow short rate, equation (2).

${ }^{10}$ This is unless smaller central banks had information about future ECB policy decisions in advance and lowered rates in anticipation of an upcoming ECB rate cut. However, we find such informational advantages to be unlikely in our sample. 
In short, under Assumptions 1 and 2, the model shows that the effect of changes in the believed lower bound on long-term interest rates decreases in the level of interest rates prevailing in a given country. In contrast, the effect of changes in expected future short-term interest rates or term premiums on long-term interest rates increases in the level of interest rates prevailing in a given country. We can thus design our empirical strategy around a sufficient condition for the presence of effects of changes in the believed lower bound on long-term interest rates. Specifically, we assess whether the effect of unexpected interest rate cuts below zero on long-term interest rates in other countries is negatively related to prevailing interest rate levels.

It should be stressed that a negative relationship between the interest rate level and the effect of foreign interest rate cuts into negative territory on long-term interest rates is a sufficient but not a necessary condition for the presence of belief effects. This is because we observe only the combined effects in the response of long-term yields to announcements. If standard spillovers are present and positively related to the interest rate level and if these outweigh the belief effects of the lower bound, the belief effects might still be there, but we would not see them. For the same reason, our approach does not allow us to identify the size of the believed lower bound effects independently of other spillovers.

\section{$3.2 \quad$ The Events}

Table 1 list the relevant policy rate cuts into negative territory undertaken so far, and Figure 2 illustrates the time paths of the policy rates of the sample countries.

A downward shift in the believed lower bound and the traditional spillovers associated with these announcements should be accompanied by a decline in interest rates in non-announcing countries. As a first assessment of the data, we have plotted the movements of 2-year yields, based on data on transactions-based intra-day interest rate swap rates from Bloomberg, in the two and a half hours following each of the announcements that were unexpected. ${ }^{11}$ Because of the global nature of the sample, some of these markets had very low liquidity and few transactions around the time of the announcements, and the data are hence not always very informative. A first look reveals that the effects of the announcements were highly heterogeneous across both countries and events. Below, we discuss the events in more detail and present those of the plots that best illustrate the findings of the model. The plots for the remaining events are presented in Appendix D.

[Figure 2 about here]

The first policy rate cut into negative territory by the Danish central bank in 2012 came just hours after a surprise ECB rate cut in positive territory, and interest rates had therefore started to decline globally well before the Danish announcement. Table 1 shows that the cut was largely expected despite the novelty of moving policy rates below zero, perhaps also reflecting that the Danish central bank had been preparing a foundation for moving into negative territory. The subsequent ECB rate cut in June 2014 was also largely expected, according to the Bloomberg

\footnotetext{
${ }^{11}$ We focus on 2-year yields on interest rate swaps; the picture is similar for 5 -, 7 - and 10-year yields.
} 
survey. The use of negative policy rates had been discussed, and the debate had evolved in the months preceding the actual cut; thus, possible effects on the believed lower bound would already have taken place by the time the ECB made its announcement (see also Lemke and Vladu 2016).

The following announcements were different. In September 2014, the ECB took the policy rate to the previous global low of -20 basis points that Denmark had already reached, and this cut was largely unexpected. As partly reflected in Figure 3, this rate cut was associated with yield declines in the euro area as well as in the US, the UK, Canada, Hungary, Poland, Switzerland, Denmark, Sweden, and Norway. Yields were declining for about one hour after the announcement (roughly until the beginning of the press conference). While these declines are consistent with a change in the market-perceived lower bound, it is common for global markets to react to ECB announcements, and a positive correlation of cross-country interest rate movements is not surprising. ${ }^{12}$

[Figure 3 about here]

The SNB's 25 basis point rate cut to $-0.25 \%$ in December 2014, after an unscheduled meeting, was unexpected. It resulted in a drop in Swiss long-term yields of about 8 basis points and was also associated with modest yield declines in the euro area, the US, UK, Canada, Hungary, Poland and Denmark, as partly shown in Figure 4. Some yields subsequently increased by the end of the event window. Interestingly, this was mainly observed in countries that were away from the lower bound at that time. SNB announcements do not normally have large effects on foreign interest rates. The fact that this announcement was unusual, in that it reached a new global low of negative interest rates, may have made it different.

[Figure 4 about here]

The SNB's 50 basis point rate cut to $-0.75 \%$ in January 2015 was also fully unexpected and perhaps even more surprising, given how far this cut went beyond the previous global low. This cut was also associated with a decrease in Swiss long-term rates. The right panel in Figure 5 shows that the two-year rate initially dropped about 20 basis points. The 5 -year yield had dropped by 8 basis points the following day (see Table 1). Yield declines were also observed in the euro area, the US, UK, Canada, Denmark and Norway, as shown in left panel of Figure 5. The announced interest rate cut accompanied the surprise announcement of the discontinuation of the 1.20 EURCHF exchange rate floor, which led to sharp appreciation in the Swiss franc and a global spike in FX volatility and risk aversion measures. Therefore, while the observed yield movements are consistent with a change in the market-perceived lower bound, they are likely to reflect spillovers on term premiums and expectations that could have reinforced, or attenuated,

\footnotetext{
${ }^{12}$ At the press conference starting at 14:30 local time, the introduction of an asset purchase program was also announced. However, yields declined particularly in after the release of the press statement (which mentioned only the interest rate decision) and before the press conference.
} 
the effect on longer rates in other countries, underlining the need for our more rigorous approach to identification. ${ }^{13}$

[Figure 5 about here]

Just days after the Swiss announcement, the Danish central bank cut its policy rate and continued to cut it in three further separate steps over the subsequent month, reaching a negative policy rate level equal to the global low of the Swiss policy rate by February 5, 2015. Each of these steps was unexpected according to the Bloomberg survey. In general, yields dropped in Denmark, but the responses in other countries were mixed, and we do not depict them here (see Appendix D.

Sweden's Riksbank subsequently cut its policy rate on February 12, March 18 and July 2 2015 , reaching a policy rate of -35 basis points. These announcements were also unexpected, and they did not reach new global lows. The announcements were associated with important drops in Swedish yields and some downward movement in rates elsewhere. It is unlikely that the Danish and Swedish announcements in 2015 influenced the believed lower bound as much as the preceding Swiss announcements to which they were reacting, however, because they were less novel.

The ECB cut its leading policy rate further below zero on December 3, 2015, but this cut was fully expected according to the Bloomberg survey. On January 29, 2016, the Bank of Japan cut its leading policy interest rate to 10 basis points below zero. This was fully unexpected. Leading voices at the Bank of Japan had communicated just days earlier that negative interest rates were out of the question in Japan. Financial markets in Japan seemed completely unprepared, which triggered an increase in risk premiums and risk-off. While the cut was quantitatively small, the immediate impact on the believed lower bound in Japan could have been large because of the change in attitude inside the Bank of Japan that this cut could have been taken to signal. The cut was indeed associated with important long-term yield declines in Japan. In the hours following the announcement, Figure 6 shows that the two-year yield declined by 8 basis points. In the days that followed, long yields declined even more. Subsequent Bank of Japan communications have partly explained the unexpectedly large declines in long-term yields with downward shifts in the believed lower bound. ${ }^{14}$ The announcement by Bank of Japan was also associated with yield declines in the US, the euro area, Australia and New Zealand, but these declines were modest. As rates had already gone much further into negative territory elsewhere, revisions to the believed lower bound in other countries may have been small.

As in the case for the ECB, surprise announcements by the Bank of Japan normally affect markets globally, even if the believed lower bound is unaffected, calling for a more rigorous analysis of the data.

[Figure 6 about here]

\footnotetext{
${ }^{13}$ Yields in Hungary and Poland increased, potentially reflecting a perceived deterioration in financial conditions in these countries, where the private sector had borrowed heavily in Swiss francs. Because of the Swiss franc appreciation, the local currency value of these debts rose.

${ }^{14}$ See Kuroda (2016).
} 
Sweden's Riksbank again cut its policy rate on February 11, 2016, but the unexpected component of this cut was only 5 basis points. Yields in other countries tended to moderately decline after this announcement (see Appendix D).

Finally, the ECB cut its leading rate by 10 basis points to -40 basis points on March 10, 2016. This cut was expected, and we do not learn much from the market reaction to it. Yields, if anything, tended to increase in response. ${ }^{15}$ Interestingly, during the press conference following the announcement, the ECB President answered a question about how low interest rates could go with remarks about adverse consequences for the banking system of negative interest rates and the desire of the ECB's Governing Council not to signal that rates could go as "low as we want". ${ }^{16}$ At about this time, yields in other countries moderately increased.

Overall, global market movements around the announcements suggest a tendency for foreign yields to decline when announced cuts were unexpected. The data also suggest that there is a lot of variation in the market response across these unexpected announcements and across countries that requires further investigation.

\subsection{Panel Investigation}

We now turn to a more formal panel data analysis of the lower bound location channel.

\subsubsection{Specification}

Our baseline panel specification is as follows:

$$
\begin{aligned}
\Delta R_{i, t} & =\beta_{0}+\beta_{1} \Delta r_{t}+\beta_{2} r_{i, t-1}+\beta_{3} \Delta r_{t} \times r_{i, t-1}+\varepsilon_{i, t} \\
\Delta R_{i, t} & =\beta_{0}+\beta_{1} \Delta r_{t}+\beta_{2} R_{i, t-1}+\beta_{3} \Delta r_{t} \times R_{i, t-1}+\varepsilon_{i, t}
\end{aligned}
$$

The index $t$ runs across the selected 12 announcement dates; the index $i$ runs across the countries in our sample excluding the country announcing at time $t$. This implies that the sample composition changes across announcements. The surprise component of the change in the policy rate in the announcing country, $\Delta r_{t}$, proxies for the revision of market views about the lower bound but also captures the standard policy spillovers through interest rates discussed above. The distance to the lower bound in the home country is measured in two alternative ways. We first use the level of the home country policy rate $r_{i, t-1}$ in specification (16). Alternatively, we use the long-term yield $R_{i, t-1}$ in specification (17), which captures the proximity of the lower bound in country $i$ over the lifetime of the long-term bond. Note that the coefficient of proportionality $\gamma$ from equation (12) is subsumed within the coefficients $\beta_{1}$ and $\beta_{3}$, while a potential non-zero mean of $v_{i, t}$ would be subsumed within $\beta_{2}$.

Focusing on specification (16) for a moment, the effect of $\Delta r_{t}$ on $\Delta R_{i, t}$ is given by $\beta_{1}+$ $\beta_{3} r_{i, t-1}$. The hypothesis that a downward revision in market views about the lower bound is

\footnotetext{
${ }^{15}$ The ECB did not introduce a tiered system for the interest rate on central bank reserves on deposit with the ECB, as had been expected, so the announcement as a whole may have been less of a stimulus than expected.

${ }^{16}$ Transcript from the ECB press conference on March 10, 2016, available at http://www.ecb.europa.eu/ press/pressconf/2016/html/is160310.en.html.
} 
associated with a decline in long-term yields and that, from equation (10), this effect is stronger for countries where interest rates are more constrained then corresponds to $\beta_{3}<0$ : if $\beta_{3}<0$, then a lower value of $r_{i, t-1}$ is associated with an increase in $\partial R_{t} / \partial \bar{r}$. Following the discussion in section 3.1, if $\beta_{3}<0$, we can interpret this as evidence that the change in the believed lower bound affected long-term interest rates and that this lower bound effect has outweighed any possible spillover effect through short-rate changes.

The coefficient $\beta_{1}$ represents $\partial R_{t} / \partial \bar{r}$ under the condition that $r_{i, t-1}=0$. Note that we cannot include episode-specific fixed effects because of the presence of $\Delta r_{t}$ in the regression. Therefore, we cannot account for global factors that affect the yields of all countries in $t$ in the same way - for example, changes in risk sentiment or globally relevant economic news. The coefficient $\beta_{1}$ is then difficult to interpret because it reflects both the effect of negative interest rate announcements when $r_{i, t-1}=0$ and other episode-specific global movements in yields. A priori, one would not expect the change in yields in any particular episode to depend on the initial yield level; thus, we expect $\beta_{2}=0 .{ }^{17}$

\subsubsection{Sample and Data}

Our sample of countries comprises Australia, Canada, Czech Republic, Denmark, the euro area, Hungary, Japan, New Zealand, Norway, Poland, Sweden, Switzerland, the UK and the US. This sample is chosen to include countries where policy rates have been likely to be directly constrained by the believed location of the lower bound (Denmark, Switzerland, Sweden, Japan, and the euro area), countries that have been somewhat constrained (the UK and US), and some that have been more comfortably away from the lower bound, such as Australia and New Zealand, as well as Poland and Hungary, to some degree. ${ }^{18}$ We have a total of 155 observations, based on 13 countries (14 less announcing) times 12 announcements, excluding Denmark for ECB's September 2014 announcement, where Denmark subsequently cut its own policy rate.

As the dependent variable, we use the daily change in yields on interest rate swaps ICAP series from Datastream, which according to Datastream are computed using data as of 5pm CET for all sample countries. The short rate in the swap is the 3-month rate. The advantage of this dataset is that the yield is computed at exactly the same time across the sample countries, allowing us to capture the announcements. We use daily data and a one-day event window because there is very little liquidity around our negative interest rate events and because the one-day window allows yields in these countries to respond when markets open. Daily data are available for a larger set of countries. Depending on the announcement time, the one-day window is split into a short (a few hours) pre-announcement window and a longer post-announcement window (for the Bank of Japan announcement) or into a short (a few hours) post-announcement window and a longer pre-announcement window (for those European announcements that are

\footnotetext{
${ }^{17}$ However, the effect of the (policy) interest rate level $r_{i, t-1}$ on the yield change is $\beta_{2}+\beta_{3} \Delta r_{t}$. Because we are focusing on negative interest rate announcements, we have $\Delta r_{t}<0$ by construction. Therefore, the coefficient $\beta_{2}$ in itself (the effect of $r_{i, t-1}$ given that $\Delta r_{t}=0$ ) is not very meaningful. If $\beta_{3}<0$ and if the effect of $r_{i, t-1}$ is small across countries and across announcements, then we expect $\beta_{2}<0$.

${ }^{18}$ We do not include euro area countries individually since the lower bound on the short-term interest rate refers to monetary policy decisions and is hence the same across the euro area.
} 
made in the afternoon).

As explanatory variables, we use the surprise component of interest rate announcements $\left(\Delta r_{t}\right)$, as computed from the Bloomberg Survey and listed in Table 1. As measures of domestic interest rate levels, we use the central bank policy rate $\left(r_{i, t-1}\right)$ or the interest rate on the swap contract that is also used to compute the dependent variable $\left(R_{i, t-1}\right)$, as of the day prior to the announcement. The latter captures the relevance of the lower bound over the lifetime of the swap contract. Data sources and definitions are summarized in Appendix B. Summary statistics for the regression variables are presented in Table 2.

[Table 2 about here]

\subsubsection{Results}

Table 3 contains the baseline regression results. The dependent variable is the change in the long-term interest rate in basis points. The first four columns contain the results for specification (16) when the prevailing policy rate is used as a measure of the believed distance to the lower bound for all four different maturities of the dependent variable that we consider. The last four columns display the results for specification (17) where the long-term rate that is also used to compute the dependent variable is used as a measure of the believed distance to the lower bound over the lifetime of the fixed income investment in question.

[Table 3 about here]

The constant term is negative, suggesting that, on average, long-term interest rates dropped on announcement dates by two to three basis points depending on the maturity and specification. In contrast, we find that the direct effect of unexpected rate cuts is negatively proportional to the interest rate cut - often significantly so. Combined with the constant term, this could reflect average changes in macroeconomic conditions to which the rate cut in the announcing country is reacting, but it could also reflect some average effect of the cut that is independent of the size of the cut or home country interest rate level.

The estimated coefficients on the interaction term $\Delta r_{t} \times r_{i, t-1}$ have the expected negative sign and are highly statistically significant across maturities and specifications. The further away from the lower bound a country is when an unexpected policy rate cut is announced in another country, the less the home country long-term interest rate decreases on announcement dates (or the more the long-term interest rate in the home country increases on such dates). This is consistent with the theoretical prediction that negative interest rate announcements have affected yields globally by affecting market views about the lower bound and that the strength of this effect depends on the proximity of the lower bound prior to the announcements.

Quantitatively, the composite average effect of the announced cuts is not large, but as already stressed in Section 3.1, the total predicted effect does not contain information about the net effect of changes in the believed lower bound. It only suggests that it is there, as it must be 
outweighing other effects that pull in the opposite direction. Moreover, it is averaged over a set of announcements that is likely to contain episodes where the believed lower bound was not affected (attenuation bias). The isolated effect of changes in the believed lower bound is likely to be substantially larger, but we cannot assess by how much.

Overall, the baseline results lend empirical support to the presence of lower bound belief effects on average for the series of announcements of unexpected cuts below zero.

\subsection{Robustness}

We conducted a number of robustness checks for the panel approach. First, we ran the regressions while including only those announcements where new global lows were reached for policy rates: since the Danish announcement in 2012 was expected and hence cannot capture changes in the believed lower bound, this leaves the two Swiss announcements of December 2014 and January 2015. The results are shown in Table 4. The results for the parameter estimates of $\beta_{3}$ are negative and larger in size than those of the baseline specification, as could be expected if these announcements had stronger effects on the believed lower bound than the other announcements included in the sample. However, the level of significance drops considerably. This is not surprising given the substantial reduction in observations and hence degrees of freedom. ${ }^{19}$ In contrast, the constant term in this regression turns positive and becomes large, perhaps reflecting generally increasing risk premiums around those dates in non-Swiss long-term yields. The signs of $\beta_{3}$ are consistent with the hypothesis that the two SNB rate cuts below zero changed the believed lower bound abroad, however.

[Table 4 about here]

Second, we tried excluding all the observations for countries where the policy rate was already lower than the level reached by the rate cut in the announcing country. While a negative interest rate announcement in another country may still influence average perceptions about how much further down the domestic central bank is willing to cut rates in the future in such countries, the effects of the announcement could be smaller. The results are displayed in the appendix, Table 6 . The size and significance of the coefficients on the interaction terms remain largely robust to this change in sample.

Third, one could worry that the direct transmission through short rates might be stronger for low interest rate countries because announcements of negative rate cuts were mostly in Europe, where rates were generally lower than in other parts of the world. Australia and New Zealand have the highest policy rates in our sample of countries. Both are above 2\% (New Zealand as high as 3.5\%) for all observations. Poland and Hungary also have high policy rates (close to $2 \%$ ). These countries are included to add observations and variation in the interest rate level. It could, however, be that geography matters for monetary policy spillovers and

\footnotetext{
${ }^{19}$ In the specification including only the two SNB announcements, robust standard errors are markedly lower than conventional standard errors, indicating the presence of small sample bias. In Table 4, we therefore report conventional standard errors instead.
} 
that these countries saw less of a downward movement in their rates as a response to the rate announcements that we study simply because they are further away. To address this concern, we ran the regressions while excluding Australia and New Zealand and then also excluding Poland and Hungary. The results are shown in Appendix C, Tables 7 and 8. The flip side of these exclusions is that they strongly reduce the variation in the interest rate levels. With one exception, the results are robust, and the interaction terms are even larger than for the baseline specification. The exception is for the yield level specification excluding all four countries. Yet, even here, $\beta_{3}$ is negative and large, just with large standard errors.

Finally, we measured the distance to the believed lower bound by the level of the interest rate in our regressions, implicitly proxying the lower bound by zero, as we do not observe this level. The level of the lower bound is assumed to be shifting throughout the sample, however, and omitting this variation may create omitted variable bias if shifts in the level of the believed lower bound are correlated with the error terms. There is no a priori reason why such a correlation should be expected. To nevertheless check the robustness, we ran the regression by proxying the level of the believed lower bound with the level of the globally lowest interest rate in our sample. The results are presented in Appendix C, Table 9. The size and significance of the coefficients on the interaction terms are robust to this change in sample.

\section{Conclusion}

This paper studies the effects of a change in the believed location of the lower bound on the transmission of short-term interest rates to longer-term yields. Using a simple theoretical term structure model originally proposed by Ruge-Murcia (2006), we show that if interest rate cuts below zero lead market participants to adjust downward their expectations regarding how far below negative interest rates can go, this can further reduce long-term interest rates over and above the impact of the policy rate cut itself.

Using an event study of yield reactions to selected negative interest rate announcements in a panel of advanced economies, we find evidence consistent with the hypothesis that long rates indeed have tended to drop in response to downward revisions in the market's believed location of the lower bound.

These findings have important implications both for monetary policy with low interest rates and for the use of negative interest rates as a monetary policy tool. The transmission of rate cuts into negative territory is enhanced if a rate cut lowers the believed location of the lower bound. Moreover, to the extent that central banks have or are believed to have private information about the location the lower bound, communication that informs market participants about this location can have important effects on the monetary policy stance.

\section{References}

[1] Abrahams, M., T. Adrian, R.K. Crump, E. Mönch, and R. Yu (2016), "Decomposing real and nominal yield curves", Journal of Monetary Economics 84, 182-200. 
[2] Brunnermeier, M.K. and Y. Koby (2016), "The reversal interest rate: An effective lower bound on monetary policy", unpublished manuscript.

[3] Crump, R.K., S. Eusepi and E. Mönch (2016), "The term structure of expectations and bond yields", Federal Reserve Bank of New York Staff Reports no. 775.

[4] Danthine, J.P., (2016), "The interest rate unbound?", Report, Brookings Institution.

[5] Grisse, C. (2015), "The zero lower bound and movements in the term structure of interest rates", Economics Letters 131, 66-69.

[6] Hanson, S.G. and J.C. Stein (2015), "Monetary policy and long-term real rates", Journal of Financial Economics 115(3), 429-448.

[7] Kortela, T. (2016), "A shadow rate model with time-varying lower bound of interest rates", Bank of Finland Research Discussion Paper 19.

[8] Krugman, P.R. (1991), "Target zones and exchange rate dynamics", Quarterly Journal of Economics 106(3), 669-682.

[9] Kuroda, Harohiko (2016), "Re-anchoring inflation expectations via 'quantitative and qualitative monetary easing with a negative interest rate"', Remarks at the Economic Policy Symposium Held by the Federal Reserve Bank of Kansas City, August 27.

[10] Lemke, W. and A.L. Vladu (2016), "Below the zero lower bound - a shadow-rate term structure model for the euro area", Bundesbank Discussion Paper No 32/2016.

[11] Maddala, G.S. (1983), Limited-dependent and qualitative variables in eonometrics, Econometric Society Monograph No. 3, Cambridge University Press, Cambridge.

[12] Rudebusch, G.D. and E.T. Swanson, E. T. (2012), "The bond premium in a DSGE model with long-run real and nominal risks", American Economic Journal: Macroeconomics 4(1), 105-143.

[13] Ruge-Murcia, F.J. (2006), "The expectations hypothesis of the term structure when interest rates are close to zero", Journal of Monetary Economics 53(7), 1409-1424.

[14] Swanson, E.T. and J.C. Williams (2014), "Measuring the effect of the zero lower bound on medium- and longer-term interest rates", American Economic Review 104(10), 3154-3185. 
Table 1: Negative interest rate announcements

\begin{tabular}{|c|c|c|c|c|c|c|c|}
\hline Country & Date, time & Policy rate type & $\begin{array}{l}\text { Prev. } \\
\text { pol. rate } \\
(\%)\end{array}$ & $\begin{array}{l}\text { Pol. } \\
\text { rate } \\
\text { change } \\
\text { (bp) }\end{array}$ & $\begin{array}{l}\text { Surpr. } \\
\text { comp. }^{a} \\
\text { (bp) }\end{array}$ & $\begin{array}{l}\text { Gov. yield } \\
\text { change }^{\mathrm{b}}\end{array}$ & Additional policy announcements \\
\hline Switzerland & $15.01 .15,10: 31$ & Sight deposits & -0.25 & -50 & -50 & -8 & $\begin{array}{l}\text { Discontinue minimum exchange rate. Lower target range for } \\
\text { the } 3 \text { month Libor from }(-0.75 \% \text { to } 0.25 \%) \text { to }(-1.25 \% \text { to }- \\
0.25 \%)\end{array}$ \\
\hline Switzerland & $18.12 .14,08: 00$ & Sight deposits & 0.00 & -25 & -25 & -8 & $\begin{array}{l}\text { Lower target range for the 3month Libor to }(-0.75 \% \text { to } \\
0.25 \%) \text {. Exemption threshold for neg. rates }\end{array}$ \\
\hline Euro area & $10.03 .16,13: 45$ & Deposit facility & -0.3 & -10 & 0 & 8 & $\begin{array}{l}\text { Main refinancing rate decreased by } 5 \mathrm{Bp} \text { to } 0 \% \text {, lending fa- } \\
\text { cility decreased by } 5 \mathrm{Bp} \text { to } 0.25 \% \text {. Monthly asset purchase } \\
\text { program expanded to } 80 \text { billion. Launch new } 4 \text {-year targeted } \\
\text { longer-term-refinancing operations. Add. bonds eligible for } \\
\text { regular purchases. }\end{array}$ \\
\hline Euro area & $03.12 .15,13: 45$ & Deposit facility & -0.20 & -10 & 0 & 18 & $\begin{array}{l}\text { Other rates unchanged. Continue asset purchase program } \\
\text { until March 2017. Expected was an increase in monthly pur- } \\
\text { chase volume. }\end{array}$ \\
\hline Euro area & $04.09 .14,13: 45$ & Deposit facility & -0.10 & -10 & -10 & -4 & $\begin{array}{l}\text { Interest rate on main refinancing operations decreased by } \\
10 \mathrm{Bp} \text { to } 0.05 \% \text {. Interest rate on marginal lending facility } \\
\text { decreased by } 10 \mathrm{Bp} \text { to } 0.30 \% \text {. Introduction of asset-backed } \\
\text { securities and covered bond purchase programs. }\end{array}$ \\
\hline Euro area & $05.06 .14,13: 45$ & Deposit facility & -0.0 & -10 & 0 & -3 & $\begin{array}{l}\text { Interest rate on main refinancing operations decreased by } \\
10 \mathrm{Bp} \text { to } 0.15 \% \text {. Interest rate on marginal lending facility } \\
\text { decreased by } 35 \mathrm{Bp} \text { to } 0.40 \% \text {. Introduction of targeted longer- } \\
\text { term refinancing operations. }\end{array}$ \\
\hline Japan & $29.01 .16,04: 38$ & Current accounts & 0.00 & -10 & -10 & -7 & $\begin{array}{l}\text { Three-tier system, determining which rate applies. Loan } \\
\text { Support Program, Funds-Supplying Operations. }\end{array}$ \\
\hline Sweden & $11.02 .16,09: 30$ & Repo rate & -0.35 & -15 & -5 & -4 & $\begin{array}{l}\text { Continue govt. bond purchases for } 6 \text { months, reinvest yields } \\
\text { from current portfolio }\end{array}$ \\
\hline Sweden & $02.07 .15,09: 30$ & Repo rate & -0.25 & -10 & -10 & -5 & Extend govt. bond purchases by SEK 45 billion \\
\hline Sweden & $18.03 .15,09: 30$ & Repo rate & -0.1 & -15 & -15 & -11 & Extend govt. bond purchases by SEK 30 billion \\
\hline Sweden & $12.02 .15,09: 30$ & Repo rate & 0.00 & -10 & -10 & -15 & Extend govt. bond purchases by SEK 10 billion \\
\hline Denmark & $05.02 .15,16: 00$ & Cert. Deposit & -0.50 & -25 & -25 & -5 & - \\
\hline Denmark & $29.01 .15,16: 00$ & Cert. Deposit & -0.35 & -15 & -15 & -1 & - \\
\hline Denmark & $22.01 .15,16: 00$ & Cert. Deposit & -0.20 & -15 & -15 & -2 & - \\
\hline Denmark & $19.01 .15,16: 00$ & Cert. Deposit & -0.05 & -15 & -15 & -6 & - \\
\hline Denmark & $04.09 .14,16: 00$ & Cert. Deposit & 0.05 & -10 & 0 & -5 & - \\
\hline Denmark & $05.07 .12,16: 00$ & Cert. Deposit & 0.05 & -25 & 0 & -7 & - \\
\hline
\end{tabular}

${ }^{\mathrm{b}}$ Daily \%-change of bond 5-year government bond yields. Based on data from Thomson Reuters Datastream, using constant maturity series (e.g., "GVSD03(CM05)"). Euro area yields are approximated with German government bond yields.

a The surprise component of the announced interest rate cut is computed as the difference between the announced cut and the median from the Bloomberg survey conducted among economists at domestic and international banks, usually on Fridays prior to the announcement. 
Table 2: Summary statistics

\begin{tabular}{lccccc} 
& mean & st.dev. & min & max & obs. \\
\hline & & & & & \\
Monetary policy surprises, $\Delta r_{t},(\mathrm{bps})$ & -17.92 & 12.15 & -50.00 & -5.00 & 12 \\
Central bank policy rates, $r_{i, t-1},(\%)$ & 0.89 & 1.14 & -0.75 & 3.50 & 155 \\
& & & & & \\
Yield change, $\Delta R_{i, t},(\mathrm{bps})$ & & & & & \\
\hline 2-year yields & 1.06 & 1.07 & -0.76 & 4.17 & 155 \\
5-year yields & 1.37 & 1.09 & -0.56 & 4.49 & 155 \\
7-year yields & 1.57 & 1.09 & -0.34 & 4.61 & 155 \\
10-year yields & 1.83 & 1.07 & -0.07 & 4.73 & 155 \\
& & & & & \\
Yield level, $R_{i, t-1},(\%)$ & & & & & \\
\hline 2-year yields & -1.56 & 2.97 & -9.11 & 8.10 & 155 \\
5-year yields & -1.80 & 3.87 & -12.01 & 11.52 & 155 \\
7-year yields & -1.82 & 4.25 & -14.25 & 11.45 & 155 \\
10-year yields & -1.78 & 4.72 & -15.80 & 11.60 & 155 \\
\hline \hline
\end{tabular}

Notes: We include only days of negative interest rate announcements and only dates with non-zero announcement surprises based on the median of the Bloomberg survey. We pool the data across these 12 announcements and 14 countries, but for each announcement, we exclude the announcing country, leaving 13 countries per announcement. Interest rate levels are measured in \%; interest rate changes are measured in basis points. Yields refer to daily data as of 5 p.m. CET on ICAP yields on interest rate swaps with a 3-month variable leg, obtained from Thomson Reuters Datastream.

Table 3: Panel regression results: baseline

\begin{tabular}{|c|c|c|c|c|c|c|c|c|}
\hline \multirow[b]{2}{*}{ Maturities } & \multicolumn{4}{|c|}{$\Delta R_{i, t}$} & \multicolumn{4}{|c|}{$\Delta R_{i, t}$} \\
\hline & 2 & 5 & 7 & 10 & 2 & 5 & 7 & 10 \\
\hline$\Delta r_{t}$ & $\begin{array}{l}-0.01 \\
(0.04)\end{array}$ & $\begin{array}{l}-0.06 \\
(0.07)\end{array}$ & $\begin{array}{l}-0.08 \\
(0.08)\end{array}$ & $\begin{array}{l}-0.10 \\
(0.09)\end{array}$ & $\begin{array}{l}-0.01 \\
(0.04)\end{array}$ & $\begin{array}{l}-0.05 \\
(0.07)\end{array}$ & $\begin{array}{l}-0.07 \\
(0.08)\end{array}$ & $\begin{array}{l}-0.08 \\
(0.08)\end{array}$ \\
\hline$r_{i, t-1}$ & $\begin{array}{c}-1.09^{* * *} \\
(0.39)\end{array}$ & $\begin{array}{c}-1.00^{* *} \\
(0.46)\end{array}$ & $\begin{array}{c}-0.98^{* *} \\
(0.43)\end{array}$ & $\begin{array}{c}-0.89^{* *} \\
(0.42)\end{array}$ & & & & \\
\hline$\Delta r_{t} \times r_{i, t-1}$ & $\begin{array}{c}-0.05^{* * *} \\
(0.01)\end{array}$ & $\begin{array}{c}-0.04^{* *} \\
(0.02)\end{array}$ & $\begin{array}{c}-0.03^{* *} \\
(0.01)\end{array}$ & $\begin{array}{l}-0.03^{*} \\
(0.01)\end{array}$ & & & & \\
\hline$R_{i, t-1}$ & & & & & $\begin{array}{c}-0.98^{* *} \\
(0.45)\end{array}$ & $\begin{array}{l}-0.84 \\
(0.53)\end{array}$ & $\begin{array}{l}-0.88^{*} \\
(0.48)\end{array}$ & $\begin{array}{l}-0.88^{*} \\
(0.46)\end{array}$ \\
\hline$\Delta r_{t} \times R_{i, t-1}$ & & & & & $\begin{array}{c}-0.04^{* * *} \\
(0.01)\end{array}$ & $\begin{array}{c}-0.03^{* *} \\
(0.01)\end{array}$ & $\begin{array}{c}-0.03^{* * *} \\
(0.01)\end{array}$ & $\begin{array}{c}-0.03^{* *} \\
(0.01)\end{array}$ \\
\hline constant & $\begin{array}{c}-1.50^{* *} \\
(0.73)\end{array}$ & $\begin{array}{c}-2.54^{* *} \\
(1.20)\end{array}$ & $\begin{array}{c}-2.92^{* *} \\
(1.40)\end{array}$ & $\begin{array}{l}-3.19^{*} \\
(1.65)\end{array}$ & $\begin{array}{l}-1.40^{*} \\
(0.75)\end{array}$ & $\begin{array}{l}-2.25^{*} \\
(1.25)\end{array}$ & $\begin{array}{l}-2.37 \\
(1.47)\end{array}$ & $\begin{array}{l}-2.30 \\
(1.73)\end{array}$ \\
\hline N. obs. & 155 & 155 & 155 & 155 & 155 & 155 & 155 & 155 \\
\hline$R^{2}$ & 0.08 & 0.09 & 0.10 & 0.10 & 0.07 & 0.08 & 0.09 & 0.09 \\
\hline
\end{tabular}


Table 4: Panel regression results: new global lows

\begin{tabular}{|c|c|c|c|c|c|c|c|c|}
\hline \multirow[b]{2}{*}{ Maturities } & \multicolumn{4}{|c|}{$\Delta R_{i, t}$} & \multicolumn{4}{|c|}{$\Delta R_{i, t}$} \\
\hline & 2 & 5 & 7 & 10 & 2 & 5 & 7 & 10 \\
\hline$\Delta r_{t}$ & $\begin{array}{c}0.18^{* * *} \\
(0.07)\end{array}$ & $\begin{array}{c}0.26^{\text {**** }} \\
(0.09)\end{array}$ & $\begin{array}{c}0.27^{* * * *} \\
(0.08)\end{array}$ & $\begin{array}{c}0.28^{* * *} \\
(0.09)\end{array}$ & $\begin{array}{c}0.18^{* *} \\
(0.08)\end{array}$ & $\begin{array}{c}0.25^{* *} \\
(0.12)\end{array}$ & $\begin{array}{c}0.27^{* *} \\
(0.13)\end{array}$ & $\begin{array}{l}0.30^{*} \\
(0.15)\end{array}$ \\
\hline$r_{i, t-1}$ & $\begin{array}{l}-2.78 \\
(1.75)\end{array}$ & $\begin{array}{l}-4.13^{*} \\
(2.34)\end{array}$ & $\begin{array}{c}-4.07^{*} \\
(2.19)\end{array}$ & $\begin{array}{c}-4.40^{*} \\
(2.31)\end{array}$ & & & & \\
\hline$\Delta r_{t} \times r_{i, t-1}$ & $\begin{array}{l}-0.08^{*} \\
(0.04)\end{array}$ & $\begin{array}{l}-0.11^{*} \\
(0.06)\end{array}$ & $\begin{array}{l}-0.10^{*} \\
(0.06)\end{array}$ & $\begin{array}{l}-0.10^{*} \\
(0.06)\end{array}$ & & & & \\
\hline$R_{i, t-1}$ & & & & & $\begin{array}{l}-2.20 \\
(1.98)\end{array}$ & $\begin{array}{l}-2.55 \\
(2.53)\end{array}$ & $\begin{array}{l}-2.22 \\
(2.49)\end{array}$ & $\begin{array}{l}-2.44 \\
(2.68)\end{array}$ \\
\hline$\Delta r_{t} \times R_{i, t-1}$ & & & & & $\begin{array}{l}-0.07 \\
(0.05)\end{array}$ & $\begin{array}{l}-0.07 \\
(0.07)\end{array}$ & $\begin{array}{l}-0.06 \\
(0.06)\end{array}$ & $\begin{array}{l}-0.06 \\
(0.07)\end{array}$ \\
\hline constant & $\begin{array}{c}6.35^{* *} \\
(2.66)\end{array}$ & $\begin{array}{c}10.75^{* * *} \\
(3.39)\end{array}$ & $\begin{array}{c}12.10^{* * *} \\
(3.32)\end{array}$ & $\begin{array}{c}13.06^{* * *} \\
(3.50)\end{array}$ & $\begin{array}{l}6.21^{*} \\
(3.21)\end{array}$ & $\begin{array}{c}10.47^{* *} \\
(4.72)\end{array}$ & $\begin{array}{c}11.80^{* *} \\
(5.05)\end{array}$ & $\begin{array}{c}13.49^{* *} \\
(6.00)\end{array}$ \\
\hline $\begin{array}{r}\text { N. obs. } \\
R^{2}\end{array}$ & 26 & 26 & 26 & 26 & 26 & 26 & 26 & 26 \\
\hline$R^{2}$ & 0.26 & 0.29 & 0.33 & 0.33 & 0.21 & 0.22 & 0.25 & 0.25 \\
\hline
\end{tabular}

Notes: Only 'new global low' surprise announcements are included (Switzerland Dec 2014 and Jan 2015). Because conventional standard errors for these regressions are lower than cluster-robust standard errors (for all coefficients), we here report conventional standard errors in parentheses. Statistical significance indicated with ${ }^{* * *}$ if $p<0.01,{ }^{*}$ if $p<0.05$ and $*$ if $p<0.1 . \Delta R_{i, t}$ for the announcing country has been excluded. 


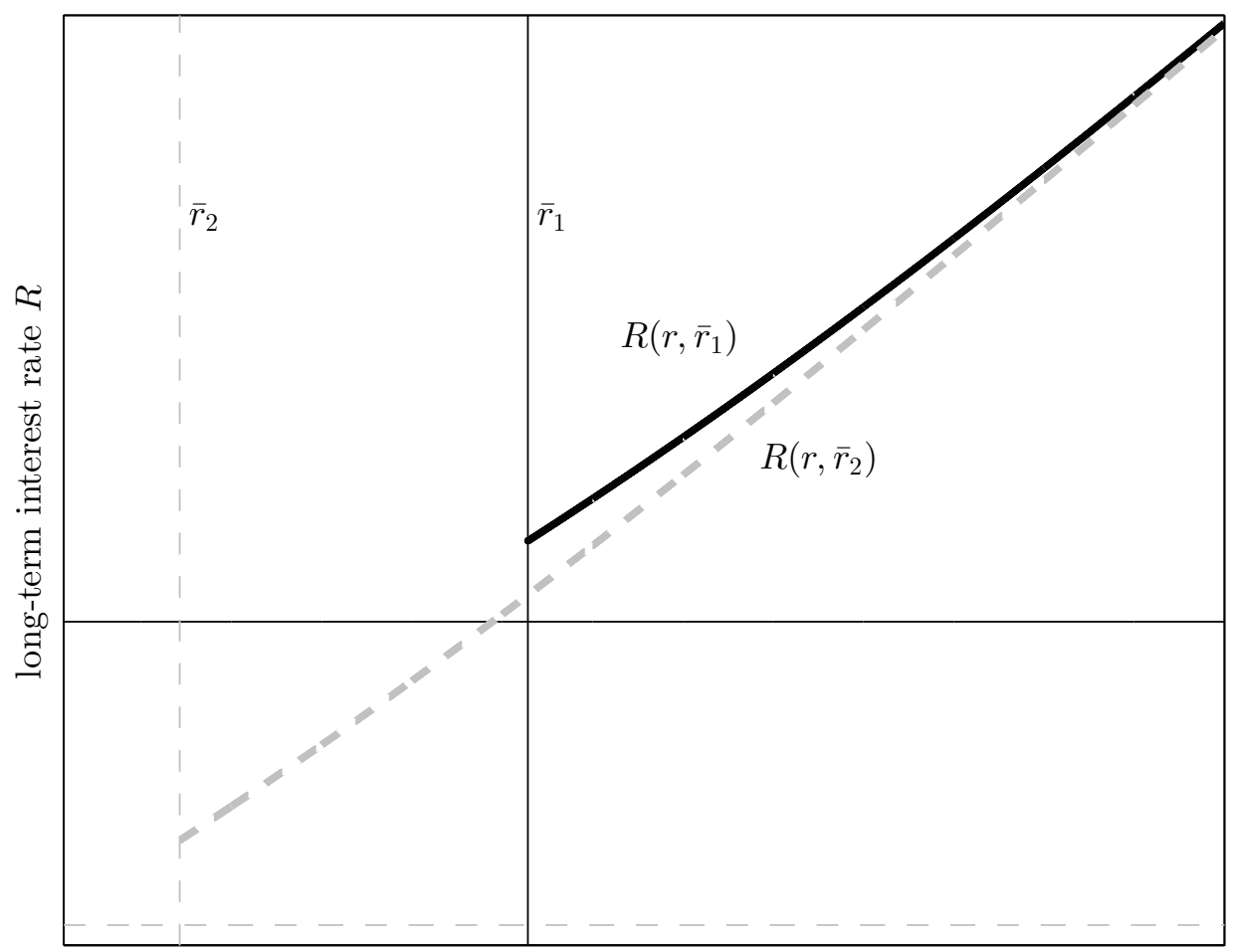

short-term interest rate $r$

Figure 1: Illustration of the link between the short-term interest rate and the long-term interest rate in the 2-period Ruge-Murcia (2006) model. Parameters: $\alpha=0, \psi=0.95, \sigma=1$. The blue line assumes that the lower bound on the policy rate is $\bar{r}_{1}=0 \%$, while the red dotted line assumes a lower bound of $\bar{r}_{2}=-0.75 \%$. 


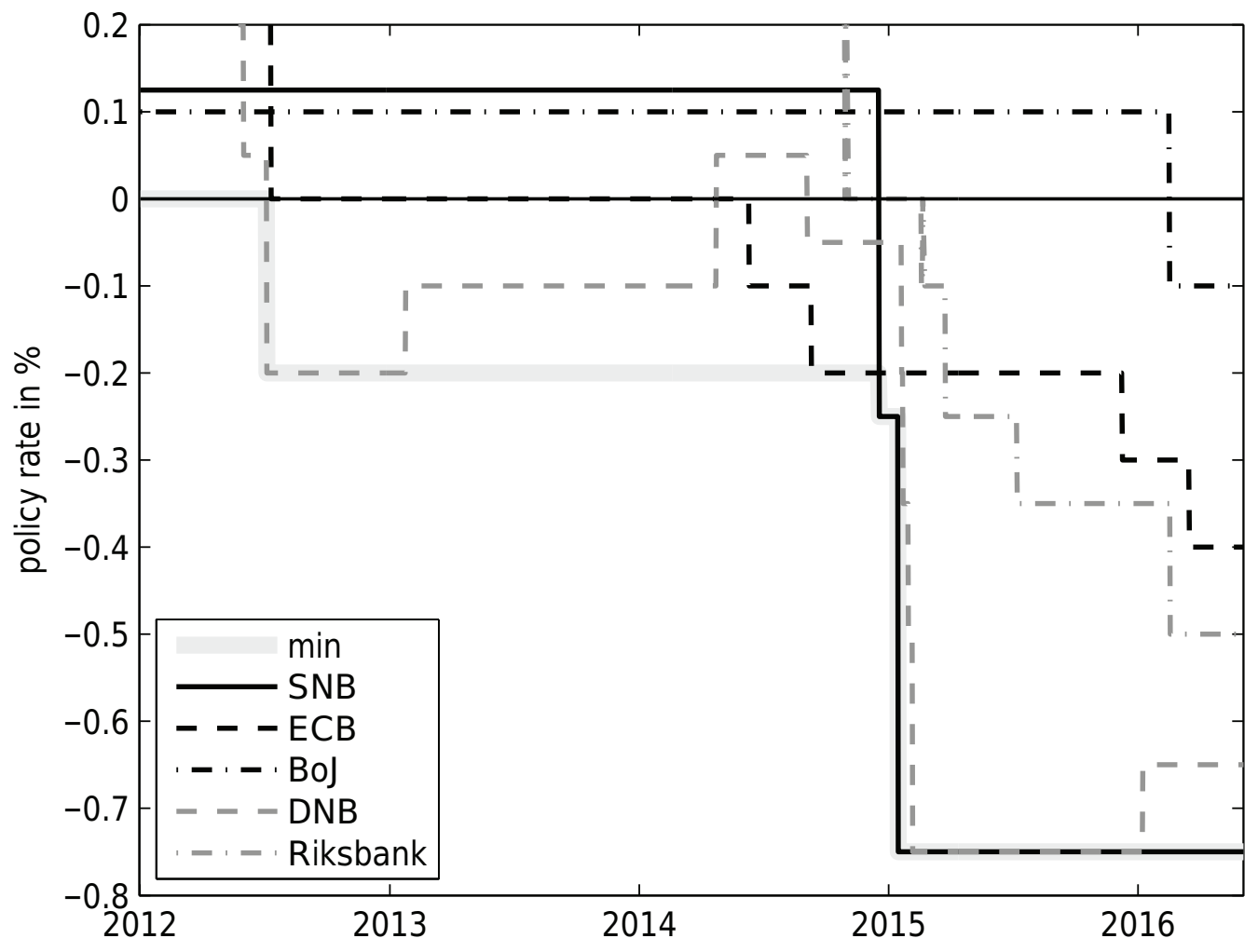

Figure 2: Overview of recent policy rate cuts below zero. SNB: 3-month Libor target rate, Datastream series SWSNBTI. ECB: euro overnight deposit rate, Datastream series S20807. Bank of Japan: main policy rate, Datastream series Y74387. Danish National Bank: rate on certificates of deposit. Datastream series S838W7. Riksbank: policy rate, Datastream series SDRATEA. 

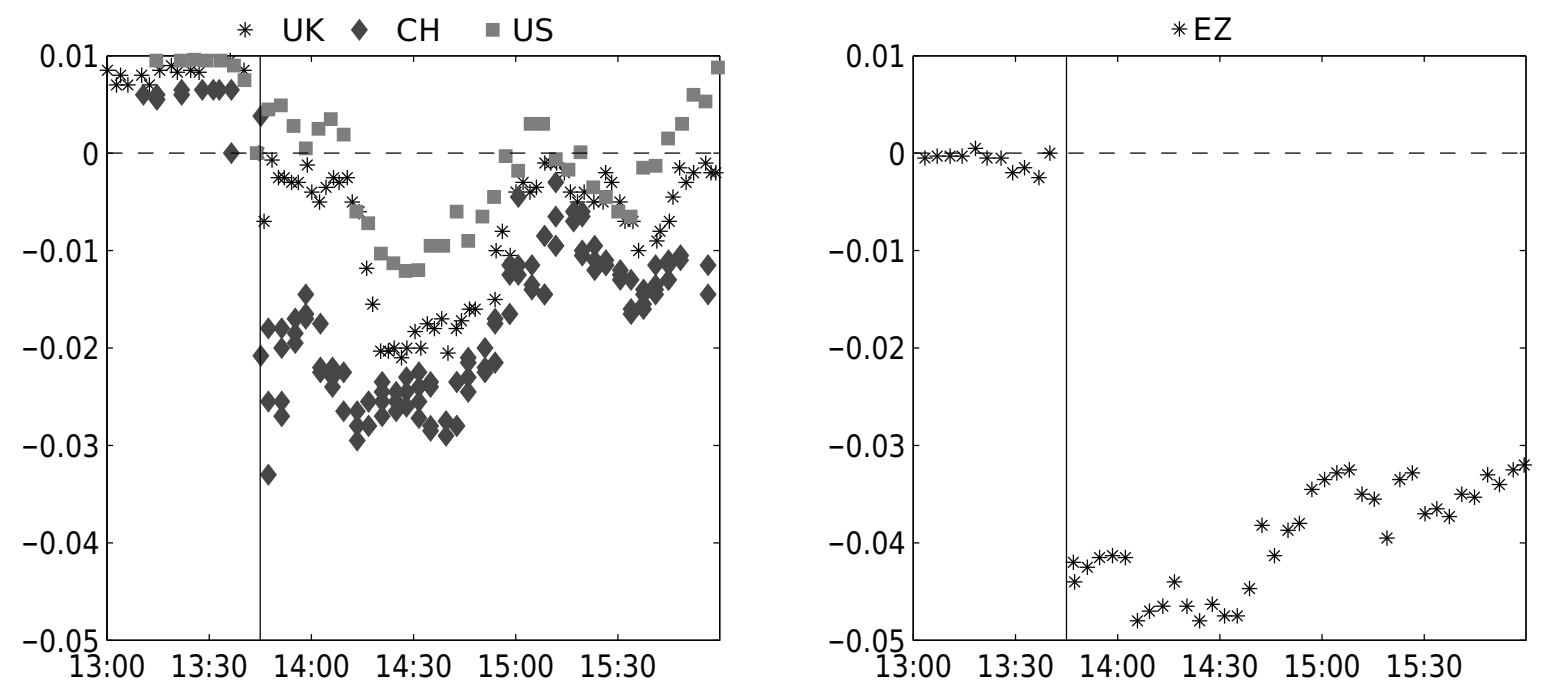

Figure 3: Response of 2-year yields on interest rate swaps around the ECB's policy announcement of September 4, 2014. The cut was unexpected and included in our sample. Vertical red lines mark the time of the announcement. Yields are normalized by adding a constant so that the average of the last two observations before the announcement is zero. Yields are based on transaction prices from Bloomberg.
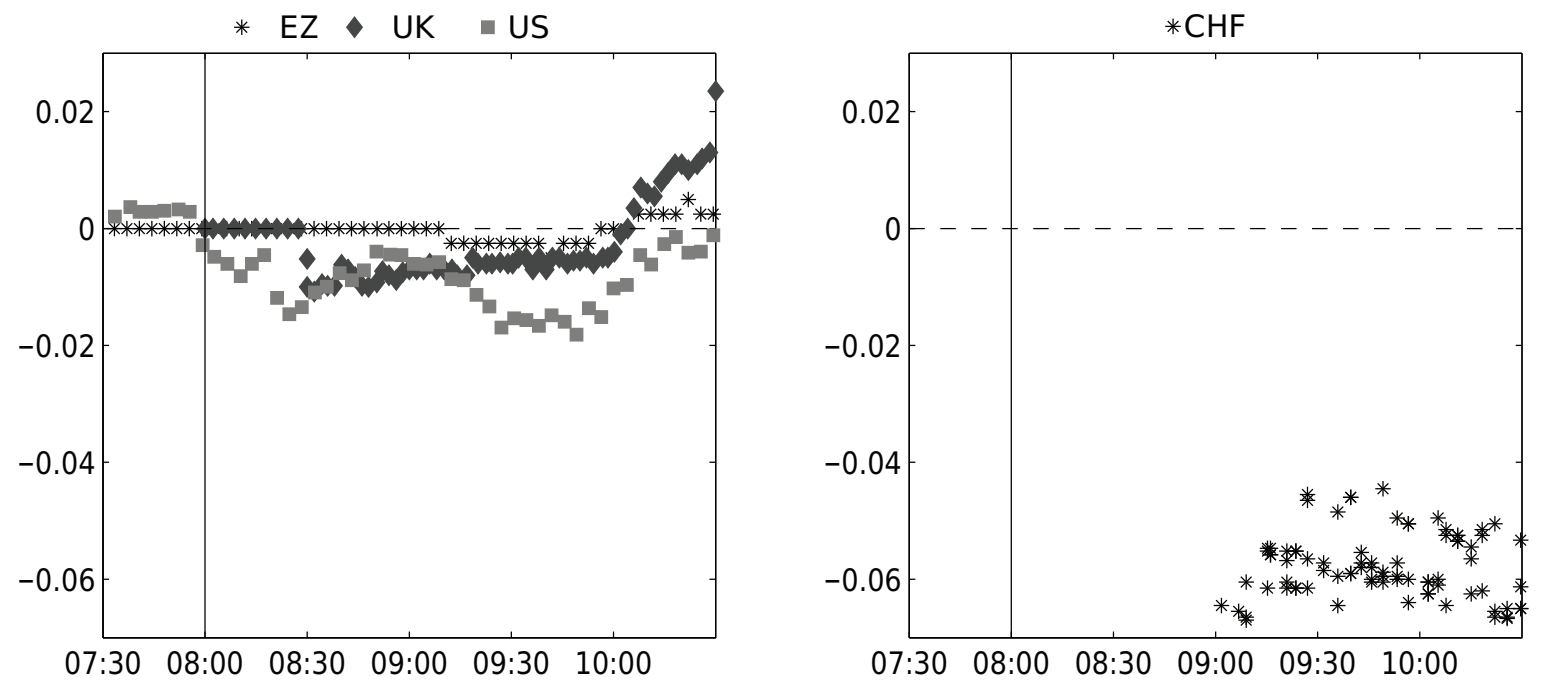

Figure 4: Response of 2-year yields on interest rate swaps around the SNB's policy announcement of December 18, 2014. The cut was unexpected and included in our sample. Vertical red lines mark the time of the announcement. Yields are normalized by adding a constant so that the average of the last two observations before the announcement is zero. Yields are based on transaction prices from Bloomberg. 

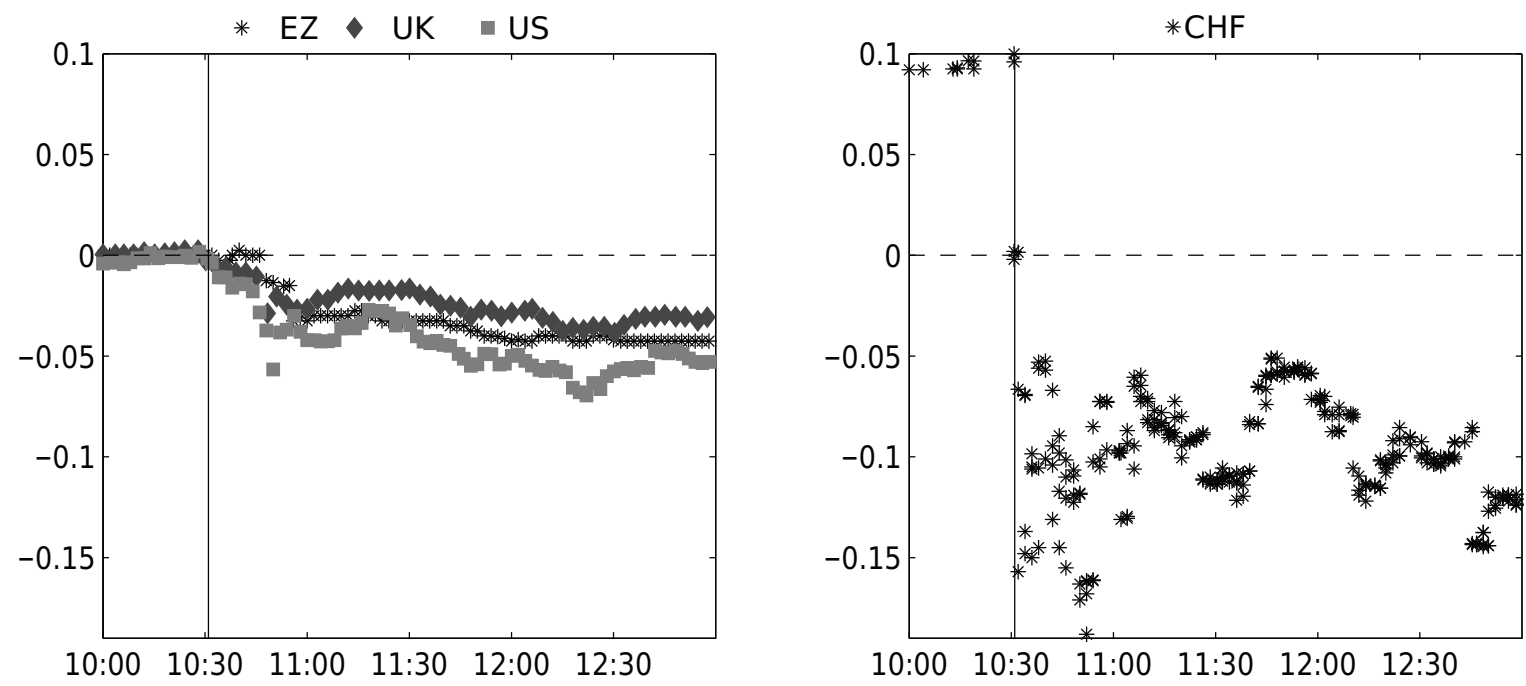

Figure 5: Response of 2-year yields on interest rate swaps around the SNB's policy announcement of January 15, 2015. The cut was unexpected and included in our sample. Vertical red lines mark the time of the announcement. Yields are normalized by adding a constant so that the average of the last two observations before the announcement is zero. Yields are based on transaction prices from Bloomberg.
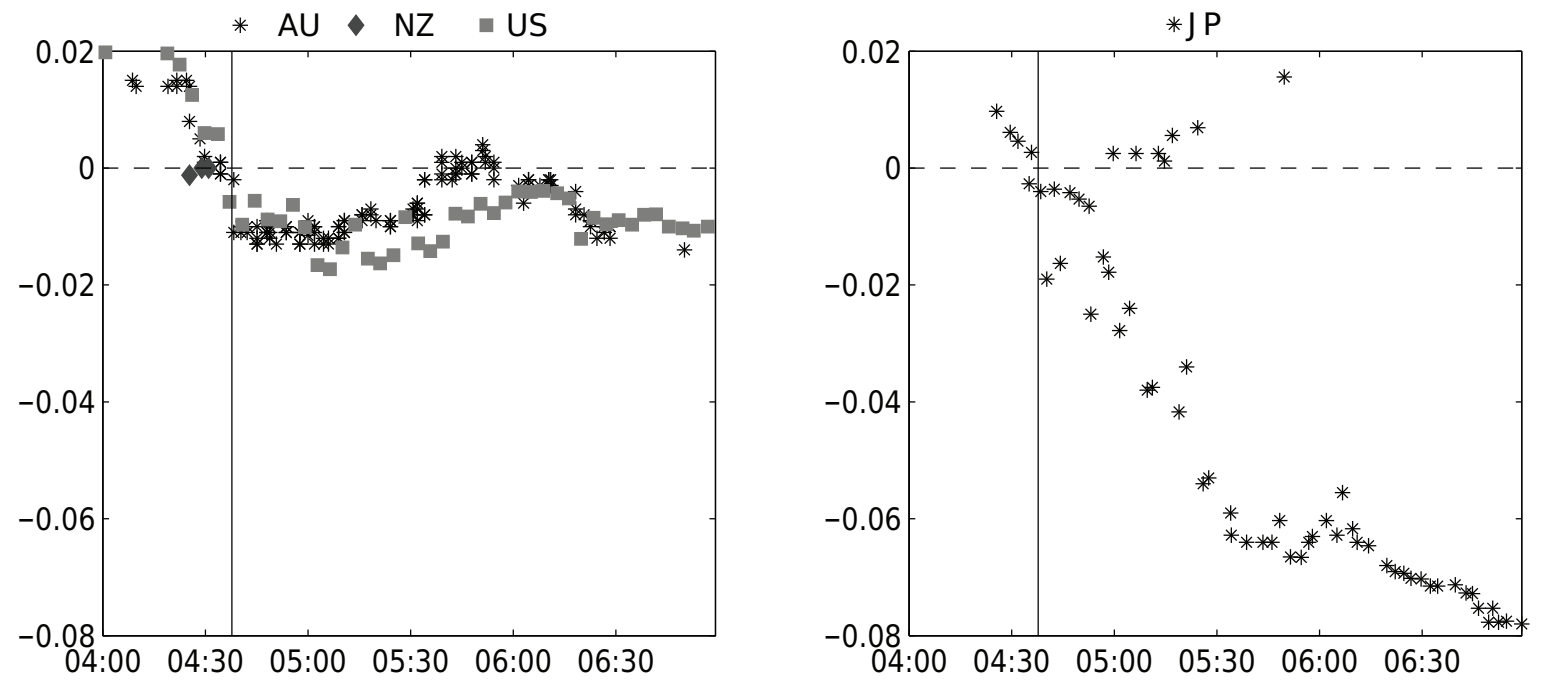

Figure 6: Response of 2-year yields on interest rate swaps around the Bank of Japan's policy announcement of January 29, 2016. The cut was unexpected and included in our sample. Vertical red lines mark the time of the announcement. Yields are normalized by adding a constant so that the average of the last two observations before the announcement is zero. Yields are based on transaction prices from Bloomberg. 


\section{Appendix}

\section{A Proof of Proposition 1}

The proof closely follows Ruge-Murcia (2006), with a slight modification to allow for a non-zero lower bound. Define $\delta_{t} \equiv \varepsilon_{t} / \sigma$ such that $\delta_{t} \sim N(0,1)$ and

$$
r_{t+1}^{*}=\mathbb{E}\left(r_{t+1}^{*}\right)+\sigma \delta_{t+1}
$$

where from $(2)$

$$
\mathbb{E}\left(r_{t+1}^{*}\right)=\alpha+\psi r_{t}
$$

Then, $r_{t+1}=r_{t+1}^{*}$ if $r_{t+1}^{*}>\bar{r}$, or equivalently, if

$$
\delta_{t+1}>\frac{\bar{r}-\mathbb{E}\left(r_{t+1}^{*}\right)}{\sigma} \equiv c_{t+1}
$$

Note that $c_{t+1}$ is observed in $t$. Thus, we have

$$
\mathbb{E}\left(r_{t+1}\right)=\mathbb{E}\left(r_{t+1} \mid \delta_{t+1}>c_{t+1}\right) \operatorname{Pr}\left(\delta_{t+1}>c_{t+1}\right)+\bar{r} \operatorname{Pr}\left(\delta_{t+1} \leq c_{t+1}\right)
$$

where

$$
\operatorname{Pr}\left(\delta_{t+1}>c_{t+1}\right)=1-\Phi\left(c_{t+1}\right)
$$

and

$$
\begin{aligned}
\mathbb{E}\left(r_{t+1} \mid \delta_{t+1}>c_{t+1}\right) & =\mathbb{E}\left(r_{t+1}^{*}\right)+\sigma \mathbb{E}\left(\delta_{t+1} \mid \delta_{t+1}>c_{t+1}\right) \\
& =\left(\bar{r}-\sigma c_{t+1}\right)+\frac{\sigma \phi\left(c_{t+1}\right)}{1-\Phi\left(c_{t+1}\right)}
\end{aligned}
$$

where the second line uses a result in Maddala (1983), page 366. Substituting back into the expression for $\mathbb{E}\left(r_{t+1}\right)$ and simplifying, we get

$$
\mathbb{E}\left(r_{t+1}\right)=\bar{r}-\sigma c_{t+1}\left(1-\Phi\left(c_{t+1}\right)\right)+\sigma \phi\left(c_{t+1}\right)
$$

which is the expression in the text. 


\section{B Data Sources and Definitions}

Table 5: Data sources and description

\begin{tabular}{|c|c|c|c|c|}
\hline Variable & Source & Datastream code & units & Description \\
\hline Monetary policy surprises & $\begin{array}{l}\text { Bloomberg } \\
\text { and national } \\
\text { central banks }\end{array}$ & $\mathrm{n} / \mathrm{a}$ & bps & $\begin{array}{l}\text { Announced policy rate change, less the } \\
\text { median from Bloomberg survey. The sur- } \\
\text { vey is conducted among financial analysts, } \\
\text { typically on the Friday before the central } \\
\text { bank decision. }\end{array}$ \\
\hline Interest rate swap yields & Datastream & $\mathrm{CCmmY03}^{*}$ & $\%$ & $\begin{array}{l}\text { Yield on interest rate swap with a variable } \\
\text { leg of } 3 \text {-months, based on prices as of } 5 \\
\text { p.m. CET London. }\end{array}$ \\
\hline \multicolumn{5}{|l|}{ Central bank policy rates } \\
\hline Reserve Bank of Australia & Datastream & RBACASH & $\%$ & Official cash rate \\
\hline Bank of Canada & Datastream & CN14309 & $\%$ & Key interest rate (target overnight rate) \\
\hline Czech National Bank & Datastream & PRREPOR & $\%$ & 2 -week repo rate \\
\hline Danmarks Nationalbank & Datastream & DKCTDEP & $\%$ & Certificates of deposits \\
\hline Central Bank of Hungary & Datastream & HNBBASE & $\%$ & Base rate \\
\hline Bank of Japan & Datastream & JPCALLT & $\%$ & Uncollateralized call rate \\
\hline Reserve Bank of New Zealand & Datastream & NZRBCSH & $\%$ & Official cash rate \\
\hline Norges Bank & Datastream & NWFOLIN & $\%$ & Sight deposit rate \\
\hline National Bank of Poland & Datastream & POPRATE & $\%$ & Reference rate (7-day bill rate) \\
\hline Sveriges Riksbank & Datastream & SDREPOR & $\%$ & Repo \\
\hline Swiss National Bank & Datastream & SWSNBTI & $\%$ & 3-month LIBOR target rate \\
\hline Bank of England & Datastream & LCBBASE & $\%$ & Base rate \\
\hline US Federal Reserve & Datastream & USFDTRG & $\%$ & Federal Funds target rate \\
\hline European Central Bank & Datastream & EURODEP & $\%$ & Overnight deposit rate \\
\hline
\end{tabular}

Notes: $* \mathrm{CC}=$ country code, $\mathrm{mm}=$ maturity. 


\section{Appendix Tables}

Table 6: Panel regression results: robustness excluding lower policy rate country observations

\begin{tabular}{|c|c|c|c|c|c|c|c|c|}
\hline \multirow[b]{2}{*}{ Maturities } & \multicolumn{4}{|c|}{$\Delta R_{i, t}$} & \multicolumn{4}{|c|}{$\Delta R_{i, t}$} \\
\hline & 2 & 5 & 7 & 10 & 2 & 5 & 7 & 10 \\
\hline$\Delta r_{t}$ & $\begin{array}{c}0.00 \\
(0.05)\end{array}$ & $\begin{array}{l}-0.06 \\
(0.08)\end{array}$ & $\begin{array}{l}-0.09 \\
(0.08)\end{array}$ & $\begin{array}{l}-0.11 \\
(0.09)\end{array}$ & $\begin{array}{c}0.01 \\
(0.05)\end{array}$ & $\begin{array}{l}-0.06 \\
(0.08)\end{array}$ & $\begin{array}{l}-0.07 \\
(0.08)\end{array}$ & $\begin{array}{l}-0.09 \\
(0.09)\end{array}$ \\
\hline$r_{i, t-1}$ & $\begin{array}{c}-1.46^{* * *} \\
(0.44)\end{array}$ & $\begin{array}{l}-1.03^{*} \\
(0.57)\end{array}$ & $\begin{array}{l}-0.93^{*} \\
(0.55)\end{array}$ & $\begin{array}{l}-0.77 \\
(0.56)\end{array}$ & & & & \\
\hline$\Delta r_{t} \times r_{i, t-1}$ & $\begin{array}{c}-0.05^{* * *} \\
(0.01)\end{array}$ & $\begin{array}{l}-0.04^{*} \\
(0.02)\end{array}$ & $\begin{array}{l}-0.03^{*} \\
(0.02)\end{array}$ & $\begin{array}{l}-0.02 \\
(0.02)\end{array}$ & & & & \\
\hline$R_{i, t-1}$ & & & & & $\begin{array}{c}-1.40^{* * *} \\
(0.53)\end{array}$ & $\begin{array}{l}-0.86 \\
(0.63)\end{array}$ & $\begin{array}{l}-0.81 \\
(0.59)\end{array}$ & $\begin{array}{l}-0.76 \\
(0.57)\end{array}$ \\
\hline$\Delta r_{t} \times R_{i, t-1}$ & & & & & $\begin{array}{c}-0.05^{* * *} \\
(0.01)\end{array}$ & $\begin{array}{l}-0.03^{*} \\
(0.02)\end{array}$ & $\begin{array}{c}-0.03^{* *} \\
(0.01)\end{array}$ & $\begin{array}{c}-0.02^{*} \\
(0.01)\end{array}$ \\
\hline constant & $\begin{array}{l}-0.90 \\
(0.81)\end{array}$ & $\begin{array}{l}-2.52^{*} \\
(1.38)\end{array}$ & $\begin{array}{l}-3.04^{*} \\
(1.58)\end{array}$ & $\begin{array}{l}-3.41^{*} \\
(1.83)\end{array}$ & $\begin{array}{l}-0.72 \\
(0.87)\end{array}$ & $\begin{array}{l}-2.28 \\
(1.49)\end{array}$ & $\begin{array}{l}-2.59 \\
(1.73)\end{array}$ & $\begin{array}{l}-2.66 \\
(2.02)\end{array}$ \\
\hline $\begin{array}{r}\text { N. obs. } \\
R^{2}\end{array}$ & $\begin{array}{l}137 \\
0.12\end{array}$ & $\begin{array}{l}137 \\
0.10\end{array}$ & $\begin{array}{l}137 \\
0.11\end{array}$ & $\begin{array}{l}137 \\
0.10\end{array}$ & $\begin{array}{l}137 \\
0.10\end{array}$ & $\begin{array}{l}137 \\
0.08\end{array}$ & $\begin{array}{l}137 \\
0.10\end{array}$ & $\begin{array}{l}137 \\
0.09\end{array}$ \\
\hline
\end{tabular}

Notes: Observations for countries where the policy rate is already lower than the policy rate reached in the announcing country are excluded. Cluster-robust standard errors in parentheses. Statistical significance indicated with *** if $p<0.01,{ }^{* *}$ if $p<0.05$ and $*$ if $p<0.1 . \Delta R_{i, t}$ for the announcing country has been excluded. 
Table 7: Panel regression results: robustness excluding Australia and New Zealand

\begin{tabular}{|c|c|c|c|c|c|c|c|c|}
\hline \multirow[b]{2}{*}{ Maturities } & \multicolumn{4}{|c|}{$\Delta R_{i, t}$} & \multicolumn{4}{|c|}{$\Delta R_{i, t}$} \\
\hline & 2 & 5 & 7 & 10 & 2 & 5 & 7 & 10 \\
\hline$\Delta r_{t}$ & $\begin{array}{l}-0.00 \\
(0.05)\end{array}$ & $\begin{array}{l}-0.05 \\
(0.07)\end{array}$ & $\begin{array}{l}-0.07 \\
(0.08)\end{array}$ & $\begin{array}{l}-0.09 \\
(0.09)\end{array}$ & $\begin{array}{c}0.01 \\
(0.05)\end{array}$ & $\begin{array}{l}-0.02 \\
(0.07)\end{array}$ & $\begin{array}{l}-0.02 \\
(0.07)\end{array}$ & $\begin{array}{l}-0.02 \\
(0.08)\end{array}$ \\
\hline$r_{i, t-1}$ & $\begin{array}{c}-1.21^{* * *} \\
(0.44)\end{array}$ & $\begin{array}{c}-1.90^{* * *} \\
(0.56)\end{array}$ & $\begin{array}{c}-2.17^{* * *} \\
(0.55)\end{array}$ & $\begin{array}{c}-2.30^{* * *} \\
(0.59)\end{array}$ & & & & \\
\hline$\Delta r_{t} \times r_{i, t-1}$ & $\begin{array}{c}-0.06^{* * *} \\
(0.02)\end{array}$ & $\begin{array}{c}-0.07^{* * *} \\
(0.03)\end{array}$ & $\begin{array}{c}-0.08^{* * *} \\
(0.03)\end{array}$ & $\begin{array}{c}-0.08^{* * *} \\
(0.03)\end{array}$ & & & & \\
\hline$R_{i, t-1}$ & & & & & $\begin{array}{c}-1.11^{* *} \\
(0.49)\end{array}$ & $\begin{array}{c}-1.65^{* * *} \\
(0.55)\end{array}$ & $\begin{array}{c}-1.90^{* * *} \\
(0.49)\end{array}$ & $\begin{array}{c}-2.02^{* * *} \\
(0.51)\end{array}$ \\
\hline$\Delta r_{t} \times R_{i, t-1}$ & & & & & $\begin{array}{c}-0.06^{* * *} \\
(0.02)\end{array}$ & $\begin{array}{c}-0.07^{* * *} \\
(0.02)\end{array}$ & $\begin{array}{c}-0.08^{* *} \\
(0.02)\end{array}$ & $\begin{array}{c}-0.07^{* * *} \\
(0.02)\end{array}$ \\
\hline constant & $\begin{array}{c}-1.45^{* *} \\
(0.73)\end{array}$ & $\begin{array}{l}-2.33^{*} \\
(1.20)\end{array}$ & $\begin{array}{l}-2.62^{*} \\
(1.41)\end{array}$ & $\begin{array}{l}-2.82^{*} \\
(1.66)\end{array}$ & $\begin{array}{l}-1.26^{*} \\
(0.76)\end{array}$ & $\begin{array}{l}-1.59 \\
(1.14)\end{array}$ & $\begin{array}{l}-1.34 \\
(1.35)\end{array}$ & $\begin{array}{l}-0.87 \\
(1.62)\end{array}$ \\
\hline N. obs. & 131 & 131 & 131 & 131 & 131 & 131 & 131 & 131 \\
\hline$R^{2}$ & 0.06 & 0.10 & 0.13 & 0.13 & 0.04 & 0.08 & 0.11 & 0.10 \\
\hline
\end{tabular}

Notes: Cluster-robust standard errors in parentheses. Statistical significance indicated with $* * *$ if $p<0.01,{ }^{* *}$ if $p<0.05$ and ${ }^{*}$ if $p<0.1 . \Delta R_{i, t}$ for the announcing country has been excluded.

Table 8: Panel regression results: robustness excluding Australia, New Zealand, Poland and Hungary

\begin{tabular}{|c|c|c|c|c|c|c|c|c|}
\hline \multirow[b]{2}{*}{ Maturities } & \multicolumn{4}{|c|}{$\Delta R_{i, t}$} & \multicolumn{4}{|c|}{$\Delta R_{i, t}$} \\
\hline & 2 & 5 & 7 & 10 & 2 & 5 & 7 & 10 \\
\hline$\Delta r_{t}$ & $\begin{array}{l}-0.00 \\
(0.04)\end{array}$ & $\begin{array}{l}-0.04 \\
(0.06)\end{array}$ & $\begin{array}{l}-0.06 \\
(0.07)\end{array}$ & $\begin{array}{l}-0.08 \\
(0.08)\end{array}$ & $\begin{array}{l}0.03^{*} \\
(0.02)\end{array}$ & $\begin{array}{c}0.01 \\
(0.03)\end{array}$ & $\begin{array}{c}0.01 \\
(0.02)\end{array}$ & $\begin{array}{c}0.01 \\
(0.03)\end{array}$ \\
\hline$r_{i, t-1}$ & $\begin{array}{l}-1.37 \\
(0.99)\end{array}$ & $\begin{array}{c}-2.56^{* * *} \\
(0.97)\end{array}$ & $\begin{array}{c}-2.64^{* * *} \\
(0.94)\end{array}$ & $\begin{array}{c}-2.62^{* *} \\
(1.01)\end{array}$ & & & & \\
\hline$\Delta r_{t} \times r_{i, t-1}$ & $\begin{array}{c}-0.10^{*} \\
(0.06)\end{array}$ & $\begin{array}{c}-0.14^{* *} \\
(0.06)\end{array}$ & $\begin{array}{c}-0.13^{* *} \\
(0.06)\end{array}$ & $\begin{array}{c}-0.12^{*} \\
(0.06)\end{array}$ & & & & \\
\hline$R_{i, t-1}$ & & & & & $\begin{array}{l}-1.12 \\
(1.22)\end{array}$ & $\begin{array}{l}-1.84 \\
(1.25)\end{array}$ & $\begin{array}{l}-1.92 \\
(1.23)\end{array}$ & $\begin{array}{l}-2.02^{*} \\
(1.21)\end{array}$ \\
\hline$\Delta r_{t} \times R_{i, t-1}$ & & & & & $\begin{array}{l}-0.10 \\
(0.08)\end{array}$ & $\begin{array}{l}-0.10 \\
(0.08)\end{array}$ & $\begin{array}{l}-0.10 \\
(0.08)\end{array}$ & $\begin{array}{l}-0.09 \\
(0.08)\end{array}$ \\
\hline constant & $\begin{array}{c}-1.38^{* *} \\
(0.67)\end{array}$ & $\begin{array}{c}-2.23^{*} \\
(1.16)\end{array}$ & $\begin{array}{c}-2.57^{*} \\
(1.38)\end{array}$ & $\begin{array}{c}-2.79^{*} \\
(1.63)\end{array}$ & $\begin{array}{l}-1.11^{*} \\
(0.57)\end{array}$ & $\begin{array}{l}-1.33 \\
(0.85)\end{array}$ & $\begin{array}{l}-1.20 \\
(0.97)\end{array}$ & $\begin{array}{l}-0.75 \\
(1.10)\end{array}$ \\
\hline $\begin{array}{r}\text { N. obs. } \\
R^{2}\end{array}$ & $\begin{array}{l}107 \\
0.05\end{array}$ & $\begin{array}{l}107 \\
0.08\end{array}$ & $\begin{array}{l}107 \\
0.08\end{array}$ & $\begin{array}{l}107 \\
0.08\end{array}$ & $\begin{array}{l}107 \\
0.04\end{array}$ & $\begin{array}{l}107 \\
0.07\end{array}$ & $\begin{array}{l}107 \\
0.07\end{array}$ & $\begin{array}{l}131 \\
0.07\end{array}$ \\
\hline
\end{tabular}

Notes: Cluster-robust standard errors in parentheses. Statistical significance indicated with $* * *$ if $p<0.01, * *$ if $p<0.05$ and $*$ if $p<0.1 . \Delta R_{i, t}$ for the announcing country has been excluded. 
Table 9: Panel regression results: Robustness to omitted variable lower bound

\begin{tabular}{|c|c|c|c|c|c|c|c|c|}
\hline \multirow[b]{2}{*}{ Maturities } & \multicolumn{4}{|c|}{$\Delta R_{i, t}$} & \multicolumn{4}{|c|}{$\Delta R_{i, t}$} \\
\hline & 2 & 5 & 7 & 10 & 2 & 5 & 7 & 10 \\
\hline$\Delta r_{t}$ & $\begin{array}{c}0.02 \\
(0.04)\end{array}$ & $\begin{array}{l}-0.04 \\
(0.07)\end{array}$ & $\begin{array}{l}-0.07 \\
(0.08)\end{array}$ & $\begin{array}{l}-0.09 \\
(0.09)\end{array}$ & $\begin{array}{c}0.02 \\
(0.04)\end{array}$ & $\begin{array}{l}-0.03 \\
(0.07)\end{array}$ & $\begin{array}{l}-0.05 \\
(0.08)\end{array}$ & $\begin{array}{l}-0.06 \\
(0.08)\end{array}$ \\
\hline$\tilde{r}_{i, t-1}$ & $\begin{array}{c}-1.18^{* * *} \\
(0.38)\end{array}$ & $\begin{array}{c}-1.07^{* *} \\
(0.45)\end{array}$ & $\begin{array}{c}-1.04^{* *} \\
(0.42)\end{array}$ & $\begin{array}{c}-0.94^{* *} \\
(0.42)\end{array}$ & & & & \\
\hline$\Delta r_{t} \times \tilde{r}_{i, t-1}$ & $\begin{array}{c}-0.05^{* * * *} \\
(0.01)\end{array}$ & $\begin{array}{c}-0.04^{* *} \\
(0.01)\end{array}$ & $\begin{array}{c}-0.04^{* * *} \\
(0.01)\end{array}$ & $\begin{array}{c}-0.03^{* *} \\
(0.01)\end{array}$ & & & & \\
\hline$\tilde{R}_{i, t-1}$ & & & & & $\begin{array}{c}-1.10^{* *} \\
(0.44)\end{array}$ & $\begin{array}{c}-0.93^{*} \\
(0.52)\end{array}$ & $\begin{array}{c}-0.95^{* *} \\
(0.48)\end{array}$ & $\begin{array}{c}-0.96^{* *} \\
(0.46)\end{array}$ \\
\hline$\Delta r_{t} \times \tilde{R}_{i, t-1}$ & & & & & $\begin{array}{c}-0.05^{* * *} \\
(0.01)\end{array}$ & $\begin{array}{c}-0.03^{* *} \\
(0.01)\end{array}$ & $\begin{array}{c}-0.03^{* * *} \\
(0.01)\end{array}$ & $\begin{array}{c}-0.03^{* * *} \\
(0.01)\end{array}$ \\
\hline constant & $\begin{array}{l}-0.77 \\
(0.82)\end{array}$ & $\begin{array}{l}-1.84 \\
(1.28)\end{array}$ & $\begin{array}{l}-2.25 \\
(1.47)\end{array}$ & $\begin{array}{l}-2.56 \\
(1.71)\end{array}$ & $\begin{array}{l}-0.68 \\
(0.91)\end{array}$ & $\begin{array}{l}-1.58 \\
(1.42)\end{array}$ & $\begin{array}{l}-1.68 \\
(1.62)\end{array}$ & $\begin{array}{l}-1.55 \\
(1.85)\end{array}$ \\
\hline N. obs. & 155 & 155 & 155 & 155 & 155 & 155 & 155 & 155 \\
\hline$R^{2}$ & 0.10 & 0.11 & 0.12 & 0.12 & 0.09 & 0.10 & 0.11 & 0.10 \\
\hline
\end{tabular}

Notes: Cluster-robust standard errors in parentheses. Statistical significance indicated with $* * *$ if $p<0.01,{ }^{*}$ if $p<0.05$ and $*$ if $p<0.1 . \Delta R_{i, t}$ for the announcing country has been excluded. $\tilde{r}_{i, t-1}$ denotes the difference between $r_{i, t-1}$ and the minimum of policy rates observed across the countries in the sample and up to $t$. A similar definition holds for $\tilde{R}_{i, t-1}$. 


\section{Appendix Figures}
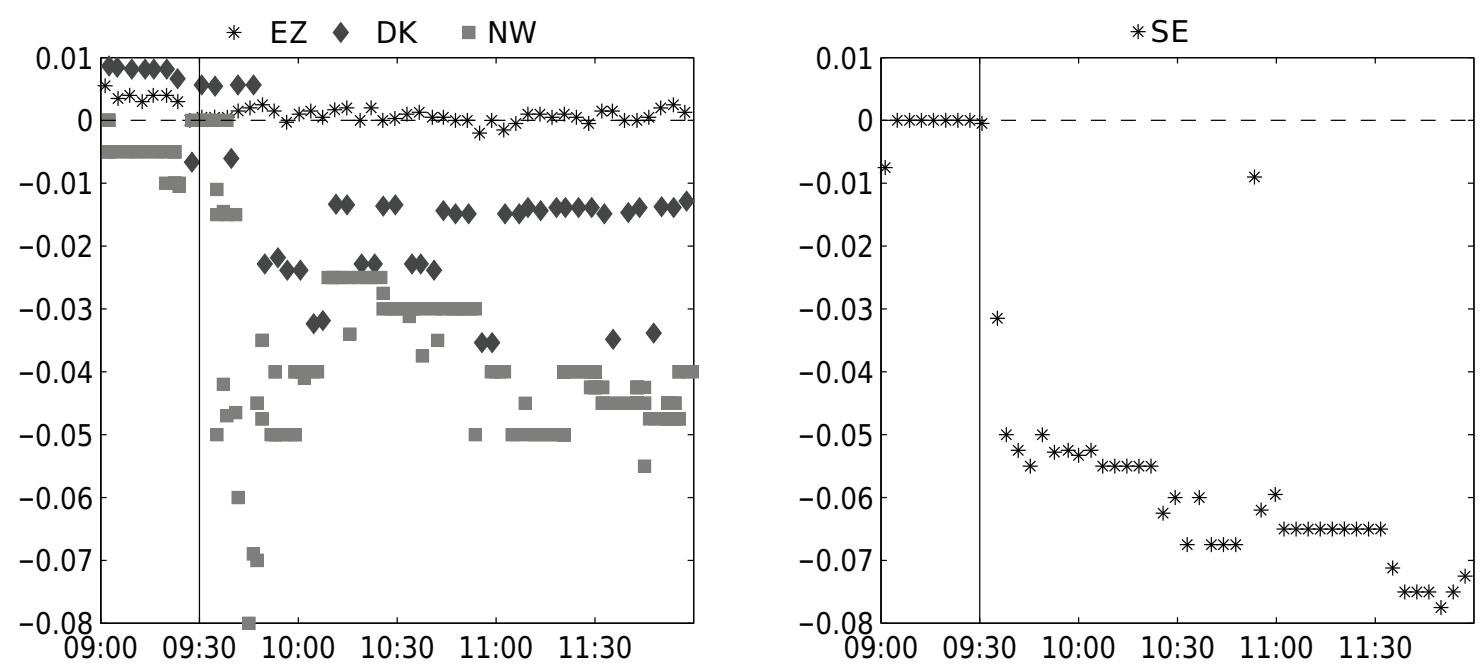

Figure 7: Response of 2-year yields on interest rate swaps around the Riksbank's policy announcement of February 12, 2015. The cut was unexpected and included in our sample. Vertical red lines mark the time of the announcement. Yields are normalized by adding a constant so that the average of the last two observations before the announcement is zero. Yields are based on transaction prices from Bloomberg. 

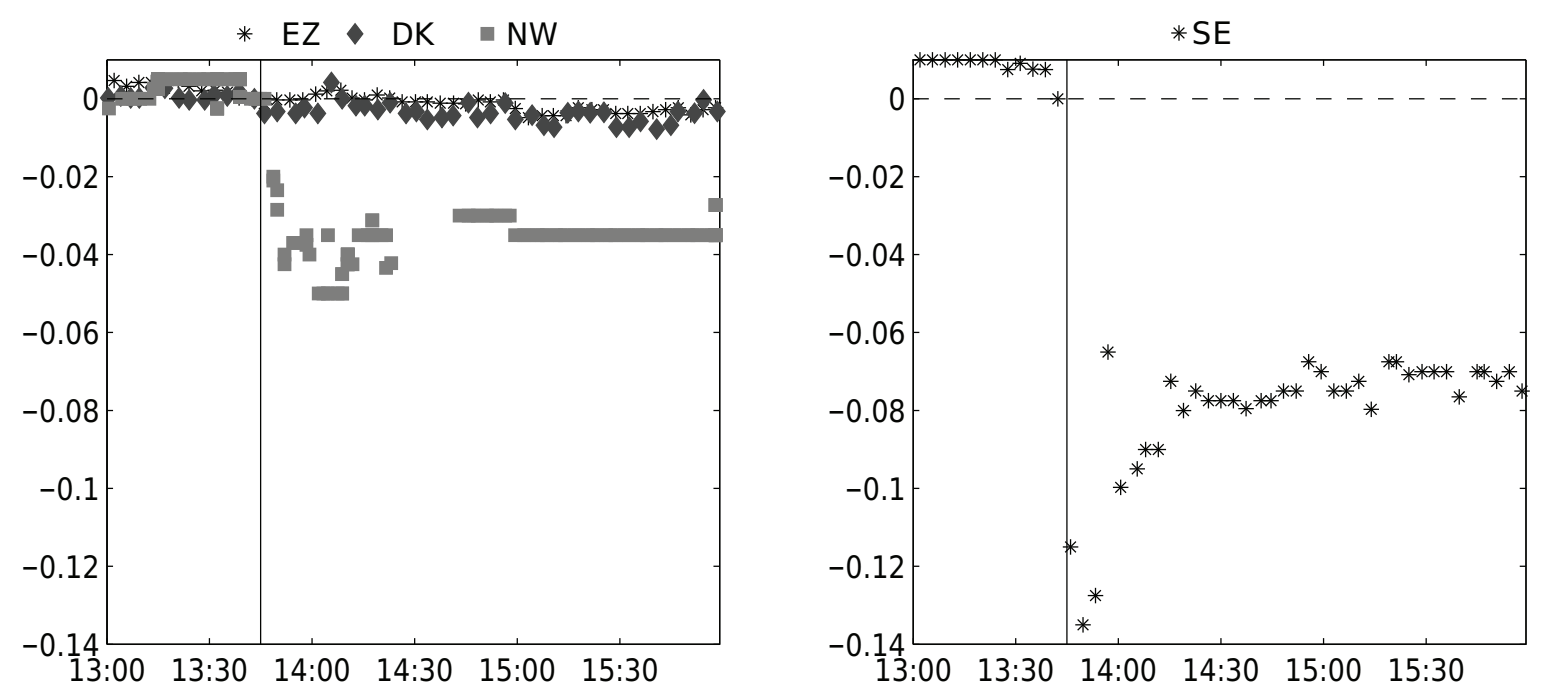

Figure 8: Response of 2-year yields on interest rate swaps around the Riksbank's policy announcement of March 18, 2015. The cut was unexpected and included in our sample. Vertical red lines mark the time of the announcement. Yields are normalized by adding a constant so that the average of the last two observations before the announcement is zero. Yields are based on transaction prices from Bloomberg.
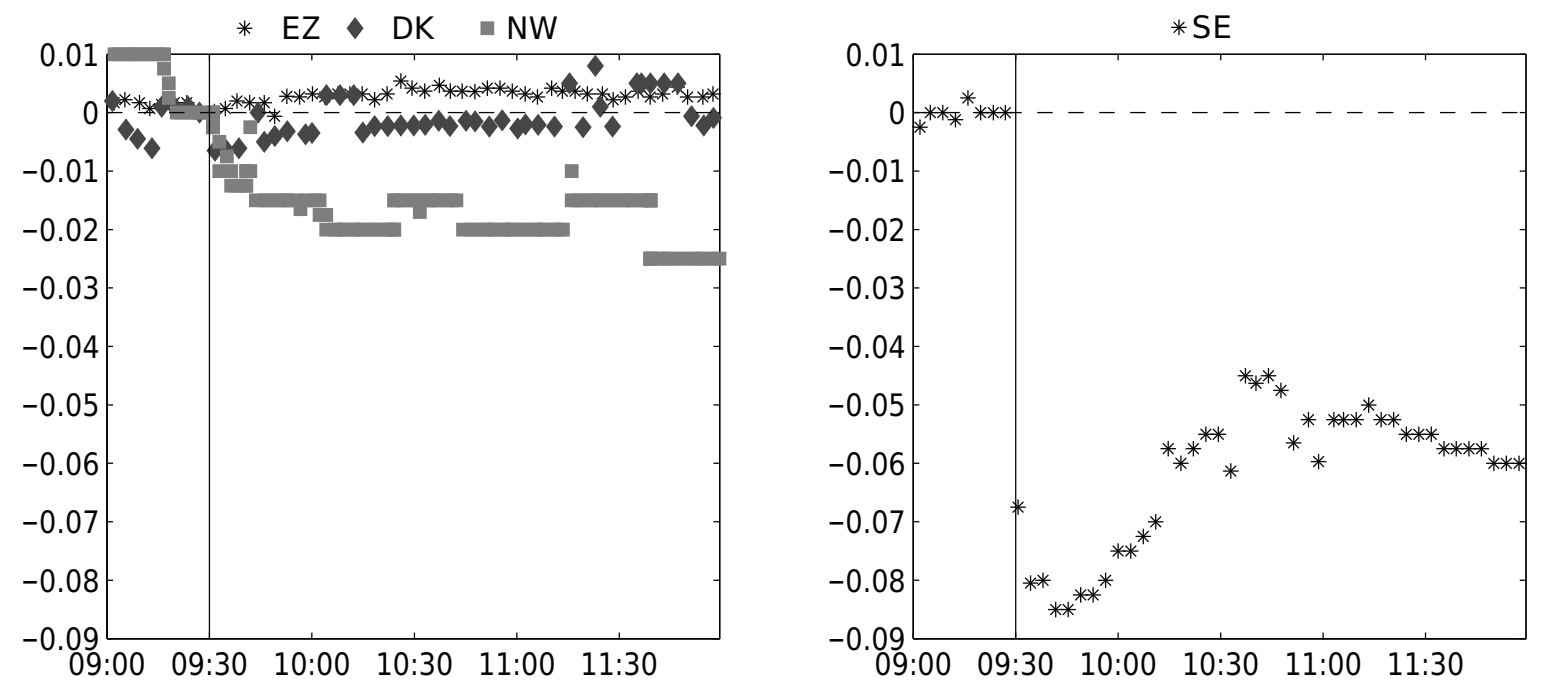

Figure 9: Response of 2-year yields on interest rate swaps around the Riksbank's policy announcement of July 2, 2015. The cut was unexpected and included in our sample. Vertical red lines mark the time of the announcement. Yields are normalized by adding a constant so that the average of the last two observations before the announcement is zero. Yields are based on transaction prices from Bloomberg. 

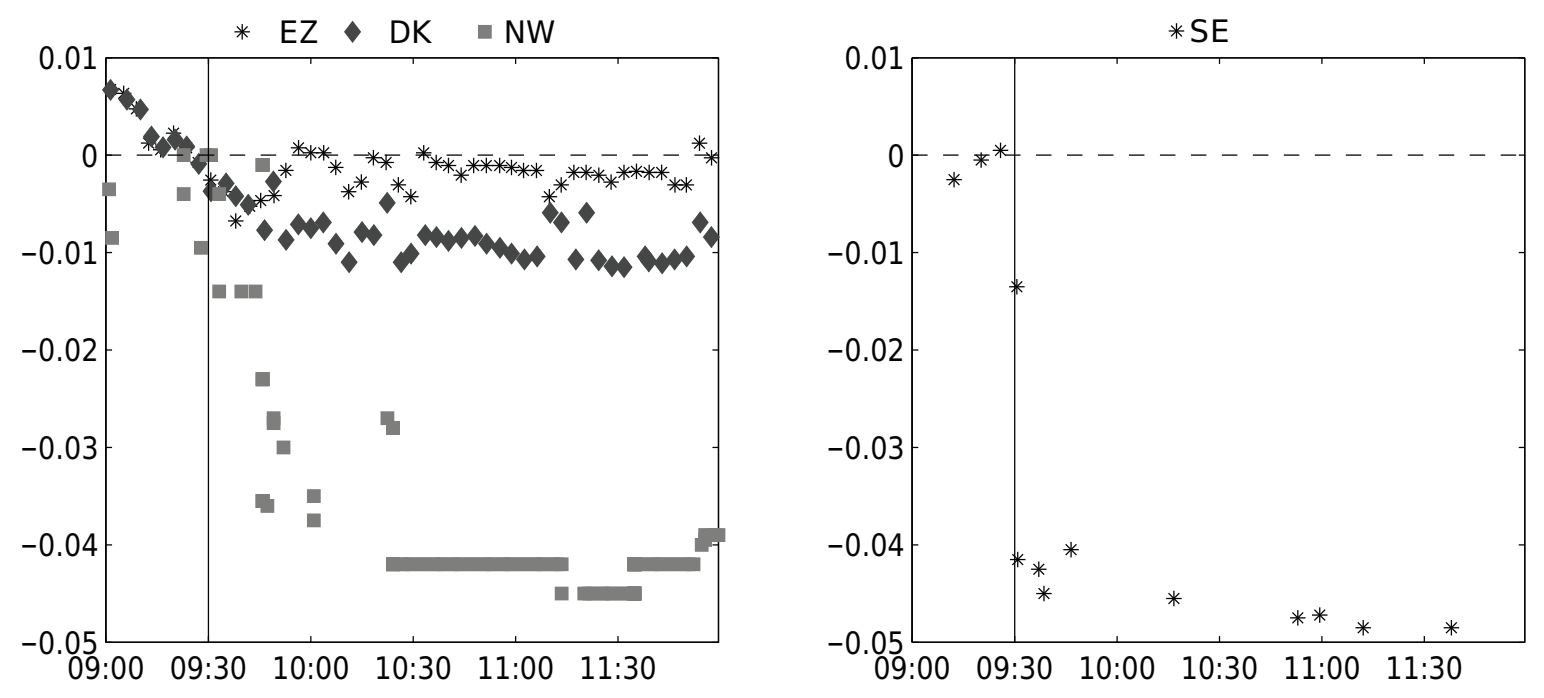

Figure 10: Response of 2-year yields on interest rate swaps around the Riksbank's policy announcement of February 11, 2016. The cut was partly unexpected and the unexpected component is included in our sample. Vertical red lines mark the time of the announcement. Yields are normalized by adding a constant so that the average of the last two observations before the announcement is zero. Yields are based on transaction prices from Bloomberg.
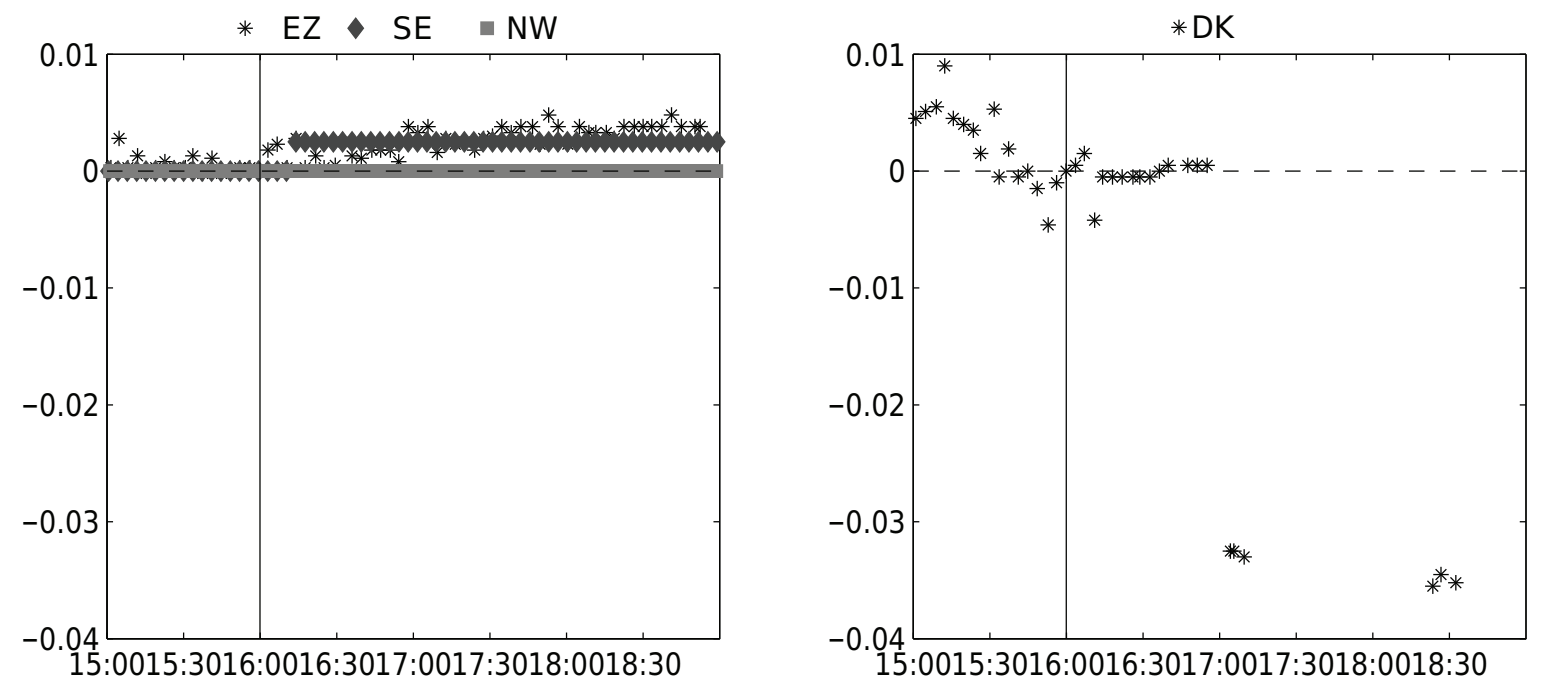

Figure 11: Response of 2-year yields on interest rate swaps around Danmarks Nationalbank's policy announcement of January 19, 2015. The cut was unexpected and included in our sample. Vertical red lines mark the time of the announcement. Yields are normalized by adding a constant so that the average of the last two observations before the announcement is zero. Yields are based on transaction prices from Bloomberg. 

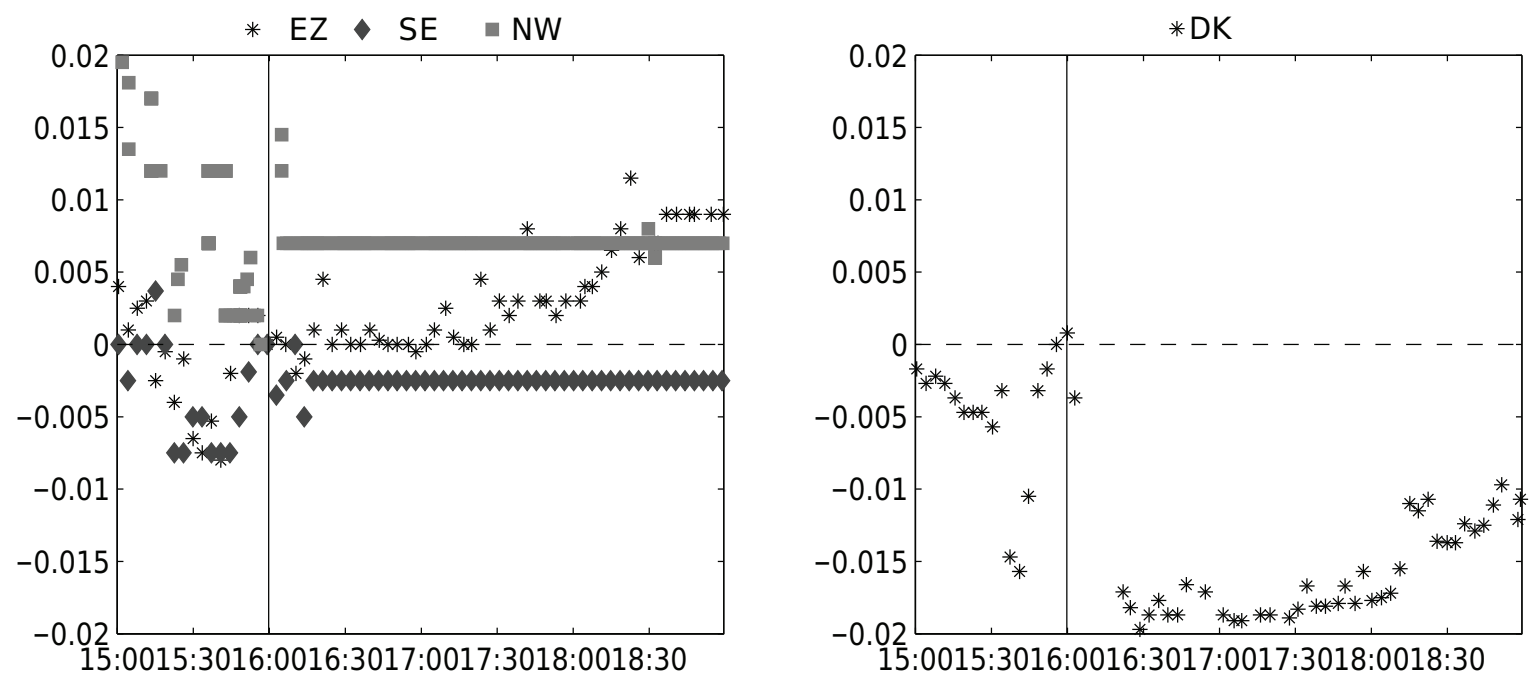

Figure 12: Response of 2-year yields on interest rate swaps around Danmarks Nationalbank's policy announcement of January 22, 2015. The cut was unexpected and included in our sample. Vertical red lines mark the time of the announcement. Yields are normalized by adding a constant so that the average of the last two observations before the announcement is zero. Yields are based on transaction prices from Bloomberg.
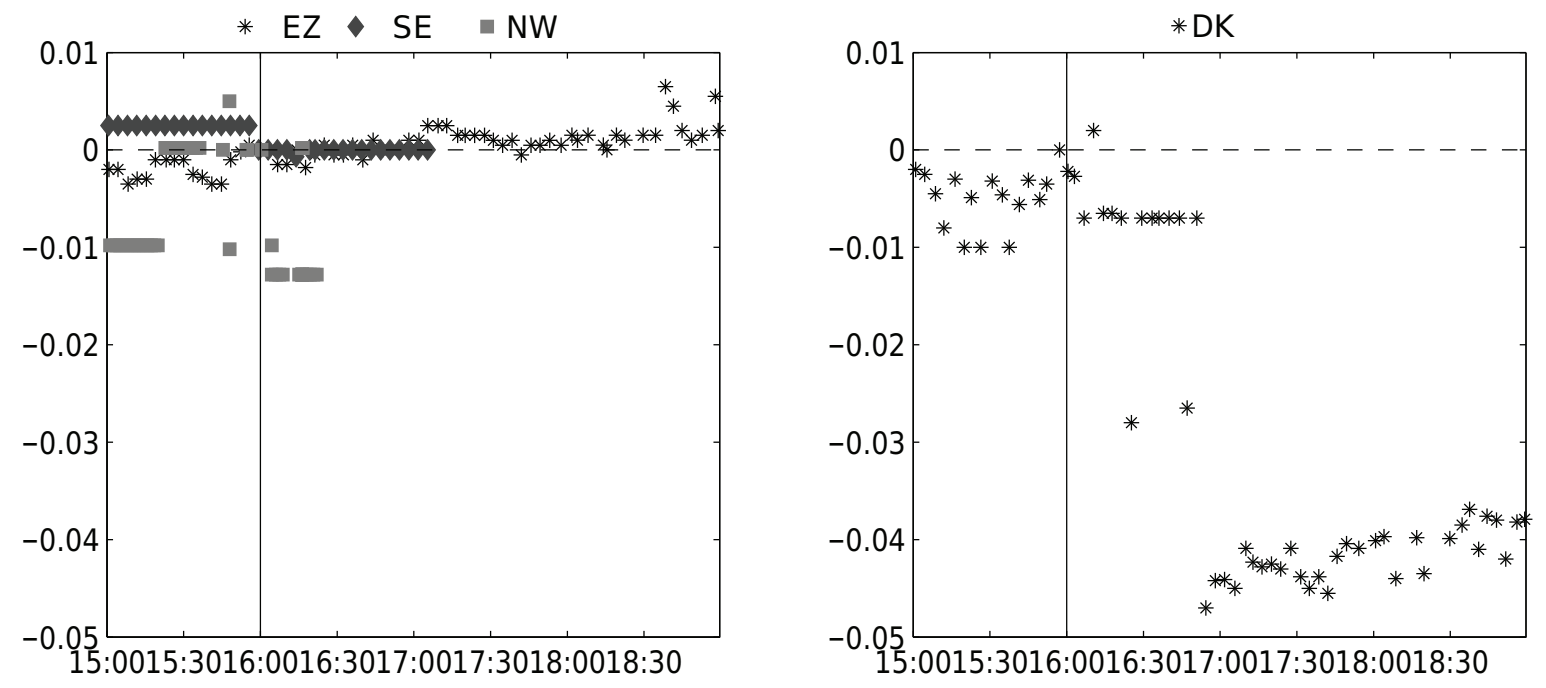

Figure 13: Response of 2-year yields on interest rate swaps around Danmarks Nationalbank's policy announcement of January 29, 2015. The cut was unexpected and included in our sample. Vertical red lines mark the time of the announcement. Yields are normalized by adding a constant so that the average of the last two observations before the announcements is zero. Yields are based on transaction prices from Bloomberg. 

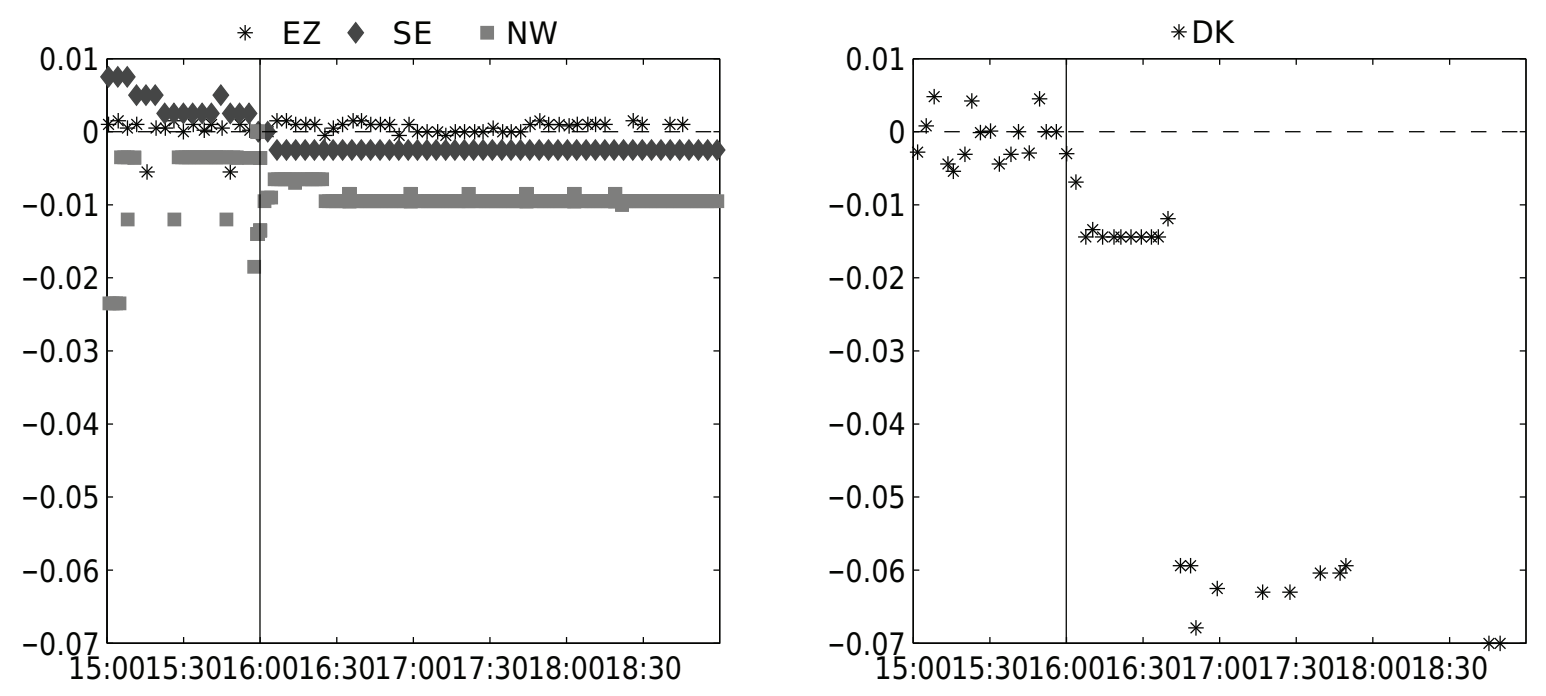

Figure 14: Response of 2-year yields on interest rate swaps around Danmarks Nationalbank's policy announcement of February 5, 2015. The cut was unexpected and included in our sample. Vertical red lines mark the time of the announcement. Yields are normalized by adding a constant so that the average of the last two observations before the announcement is zero. Yields are based on transaction prices from Bloomberg. 